\title{
inat \\ Concept, Feasibility of Cylindrical Bar Winding for Low Voltage Permanent Magnet Synchronous Motor
}

\author{
Mourad Aitakkache ${ }^{1}$, Philippe Enrici ${ }^{1, *(\mathbb{D}}$, Daniel Matt ${ }^{1}$, Nadhem Boubaker ${ }^{2}$ and Lorenzo Piscini ${ }^{3}$ \\ 1 Institut d'Electroniques et des Systèmes (IES)-CNRS UMR 5214, Université de Montpellier, \\ 34095 Montpellier, France; aitakkache@ies.univ-montp2.fr (M.A.); daniel.matt@umontpellier.fr (D.M.) \\ 2 Safran Electrical \& Power, Pitstone LU7 9GT, UK; nadhem.boubaker@safrangroup.com \\ 3 Valeo System Electrical, 94046 Creteil, France; lorenzo.piscini@valeo.com \\ * Correspondence: philippe.enrici@umontpellier.fr
}

Citation: Aitakkache, M.; Enrici, P.; Matt, D.; Boubaker, N.; Piscini, L. Concept, Feasibility of Cylindrical Bar Winding for Low Voltage Permanent Magnet Synchronous Motor. Energies 2022, 15, 1507. https://doi.org/10.3390/ en15041507

Academic Editor: Sérgio Cruz

Received: 22 December 2021

Accepted: 11 February 2022

Published: 17 February 2022

Publisher's Note: MDPI stays neutral with regard to jurisdictional claims in published maps and institutional affiliations.

Copyright: (C) 2022 by the authors. Licensee MDPI, Basel, Switzerland. This article is an open access article distributed under the terms and conditions of the Creative Commons Attribution (CC BY) license (https:// creativecommons.org/licenses/by/ $4.0 /)$.

\begin{abstract}
In this paper, we present the use of a solid bar winding for a permanent magnet synchronous motor dedicated to the electric drive of a full electric boat. For the winding, we chose to use cylindrical bars for the electric vehicle motorizations of a power lower than $10 \mathrm{~kW}$. The choice of a $60 \mathrm{VDC}$ lowvoltage power distribution requires resorting to a solid bar winding with one bar per slot (single turn). Hence, the solid conductors dissipate additional copper losses (higher AC resistance). An analysis of these additional copper losses was carried out to accurately assess the effective AC resistance of the winding and, hence, the efficiency of the electric motor. A prototype for a POD propulsion was designed, built and tested. The characteristics of its electric motor were presented. The feasibility this type of cylindrical bar winding has been proven. A study on the optimization of the slot has demonstrated the performance of this type of winding.
\end{abstract}

Keywords: additional copper losses; electric boat; permanent magnet; synchronous machine; very low voltage; solid bar winding

\section{Introduction}

In recent years, environmental questions have induced manufacturers to improve the energy performance of their systems or components. They have massively integrated electric actuators to develop electric or hybrid systems. We can mention, for example, the aeronautics field with the more electric aircraft but also the "Clean sky" program which allows for the identification of the concepts of hybrid propulsion-aeronautical systems [1]. Another field is the automobile with electric propulsion and the objective of reducing mainly $\mathrm{CO}_{2}$ emissions. We can also mention the electrification fields for agricultural machines [2], the boats [3], Ultra-Light Motorized aircraft and medium power motorizations [4].

For our small- and medium-power motorization applications used in the embedded systems, we propose to use Very Low Voltage motors. Indeed, the power supply system of the motorization of an electric vehicle is based on a battery and a static converter. The voltage level of a battery in the automobile is generally from 100 to $400 \mathrm{~V}$. For the DC network, the European directive sets the voltage level at $75 \mathrm{~V}$ for the marking of electrical equipment. In the automotive industry, the limit is lowered to $60 \mathrm{~V}$ for the approval of electric vehicles by the European standard R100 [5]. This is the voltage level we adopted for the dimensioning of our medium-power electric vehicle applications.

To increase the performance of permanent magnet-synchronous motors in terms of mass and size, we can act on different degrees of freedom such as the operating frequency, the stator winding or the topology of the machine. For example, for unconventional topologies, we can mention the Vernier Magnet Synchronous Machine which is a toothcoupled machine $[6,7]$.

To increase the performance of electric motors, research work on solid bar windings for Permanent Magnet Synchronous Machines (PMSM) has been carried out. In this work, we 
sought to increase the filling factor of the copper slots and minimize the size of the winding overhang. A massive bar winding called "hairpin" was designed for electric vehicles as shown in Figure 1 [8]. The design of this winding uses several massive-pinned conductors facilitating the overlapping of the conductors at the coil heads, and this method has been the subject of several patents $[9,10]$.
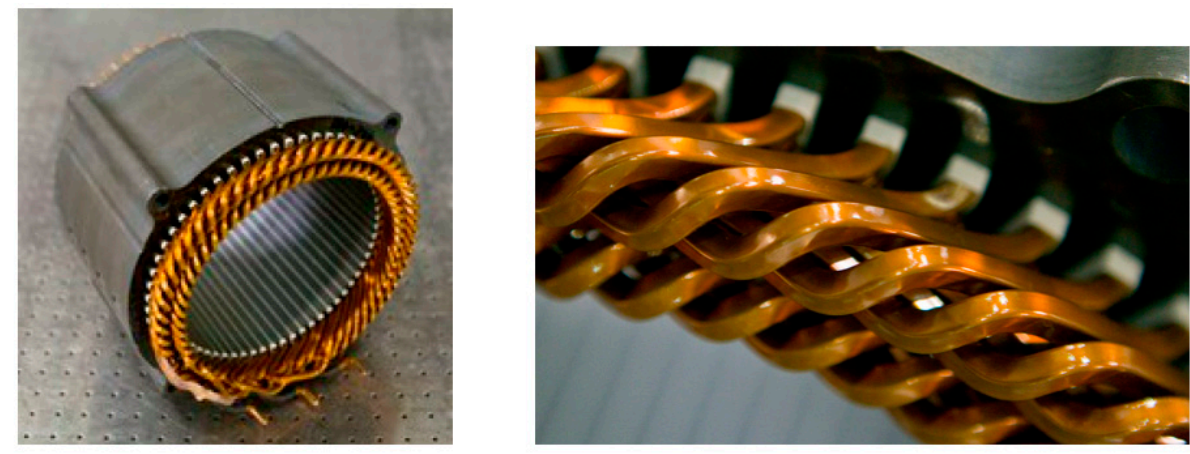

Figure 1. Motor GM-85KW for the Chevrolet Spark-Windings overhang.

The interest in using solid bars is to have a very high filling rate compared to a classic winding made of enameled round wire. The problem with the use of solid bars is the increase in additional Joule losses, especially with the increase in frequency. The studies carried out in our laboratory have allowed us to develop an original rectangular bar winding for our applications [11,12].

In this paper, a cylindrical bar-winding system is optimized for an electric-boat application with a power of $4.5 \mathrm{~kW}$ with a nominal speed of $1500 \mathrm{rpm}$. To achieve high performance, the motor is a high pole motor, $\mathrm{Nr}=52$ with permanent magnets glued to the surface of the rotor. The winding used for the motor is dental winding. This study was able to show the feasibility of such a round bar winding. A study is conducted on the analytical modeling of the additional Joule losses due to the use of massive conductors. Its additional losses are related to the shape of the bar and the operating frequency. The study allows us to demonstrate the validity of the proposed models. The characterization tests and load tests of our prototype designed and manufactured in our laboratory are presented in this article. To perform these tests, the measuring bench had to be particularly well adapted to the constraints of a low voltage and high current. A comparison between the experimental tests, finite element simulations and analytical models for the calculation of additional Joule losses is presented.

To demonstrate the degrees of freedom in the design of our type of winding, a finite element study was performed on the stator dimensions of the slot. This study allowed us to present the geometrical limits that impact on the torque and the efficiency of the motor. The compromise between the number of teeth and the number of poles was also studied. The results presented show the feasibility of a cylindrical-bar winding for low-power electric motorization applications.

\section{Bar Winding}

\subsection{Slot and Bar Winding}

The windings of electrical actuators (motor or generator) are defined mainly by their topology (diametral winding, tooth winding) but also by the shape of the slot and the associated conductors. The geometric shape of the slot is directly related to the actuator's mechanical and electrical characteristics. We present the different shapes of possible slots encountered in the windings of electrical machines in Figure 2. 

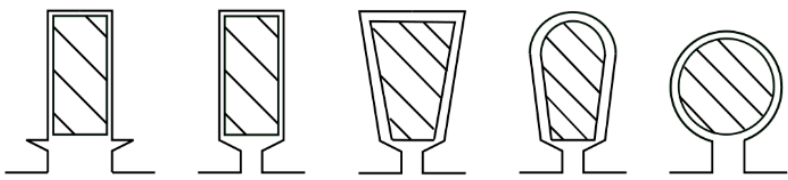

Figure 2. Various slot shapes.

Each slot is defined by its geometric shape but also by the nature of the tooth-tip and its slot opening. Indeed, the tooth-tip and the slot opening have an impact via direct interaction on the air gap of the electrical machine.

In the design of permanent magnet synchronous motors, the calculation of the electromagnetic torque $T_{e m}$ can be expressed by the Maxwell Tensor of Equation (1).

$$
T_{e m}=R_{e}^{2} \cdot L \cdot \int_{0}^{2 \pi} B_{n} \cdot H_{t} \cdot d \theta
$$

The dimensions $R_{e}$ and $L$ in Equation (1) represent the air gap radius and the active iron length, $\theta$ the mechanical angle, $B_{n}$ the normal flux density produced by the rotor and $H_{t}$. the tangential magnetic field produced by the winding.

In our calculation procedure, we use the simplified relation (2):

$$
T_{e m}=R_{e}^{2} \cdot L \cdot \int_{0}^{2 \pi} b_{1 a n} \cdot \lambda_{1} \cdot d \theta
$$

where $b_{1 a n}$ is the amplitude of the fundamental radial component $b_{n}$ of induction in the air gap due to the magnets and $\lambda_{1}$ is the amplitude of the fundamental of the tangential component $h_{t}$ of the field created by the armature currents. Additionally $\lambda_{1}$ is a linear current density that allows for the replacement of the slot currents by an equivalent thin layer producing the same amplitude $h_{1 j t}$ [13].

It is common practice to use Carter's coefficient in the calculation of $b_{1 a n}$, which makes it possible to calculate an equivalent air gap, taking into account the shape and opening of the slot.

For a classical winding, the wire is introduced through the slot opening and it is necessary to open the slot quite wide. In this case, the optimization of the slot opening is limited. In the case of bar winding, the slot opening was considered an optimization parameter because the performances related to it are:

- The output torque, because the field modulations produced due to the stator slots, impacts the fundamental of the magnetic induction;

- The cogging torque, due to the interaction between the magnet and the tooth, creates a smoother stator (closed slot) although that of the cogging torque is low. This can also lead to improvements in the vibratory and acoustic behavior of the motor;

- Losses by induced currents in the magnets or a small slot opening significantly attenuates the variation of the permeance seen by the rotor and consequently less losses by induced currents, less heating and better motor efficiency. We have the same problem when the motor has a conductive metal sleeve (e.g., Inconel which has a high resistivity).

The aerodynamic mechanical losses are proportional to the roughness coefficient that depends directly on the surface condition of the rotor and the stator.

The shape of the slot will be directly related to the leakage reactance for AC machines. The stator leakage reactance is composed of two very different terms, namely the slot-leakage reactance due to the leakage flux that closes around the conductors, and the leakage reactance of the coil heads, parts of the winding located in the air at each end of the laminations.

This slot shape plays a role in the additional losses in windings carrying alternating currents. The increase in losses is due to the non-uniform distribution of currents in the conductors. This is not so much the result of the skin effect or the Kelvin effect (increase in 
the apparent resistance of conductors carrying alternating current), but rather the influence of the leakage flow, which is transverse to the slot and creates eddy currents in the conductor mass. A reduction in the height of the conductor reduces these currents by reducing the section offered to the leakage flux. If low height conductors are used, there are always additional losses. This effect of backflow or current concentration is called the "Field effect" [14]. Finally, there is an effect caused by the rotation of the magnets that create induced currents at the slots. All these phenomena are discussed below for our bar winding.

The use of conductor bars for windings is not a new thing because they have already been used in the windings of large alternators as shown in Figure 3, Leblanc dampers and rotational conductors of induction machines with a squirrel cage (single or double) $[15,16]$, Figure 4.
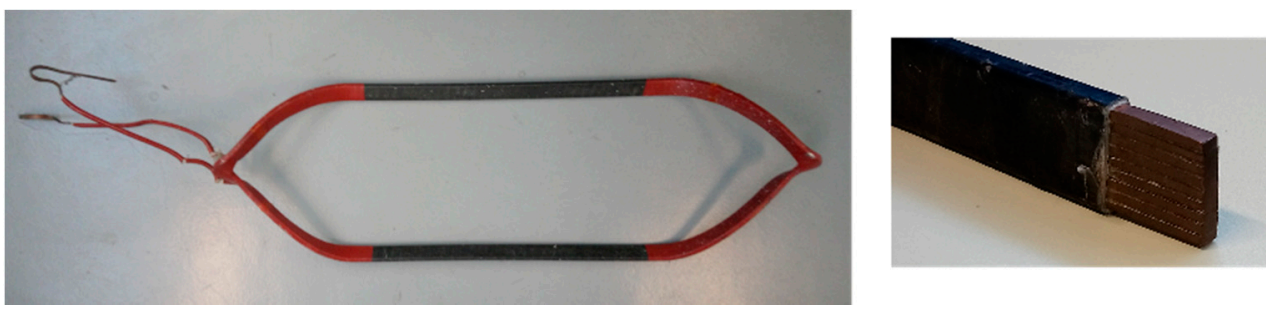

Figure 3. Bar winding.
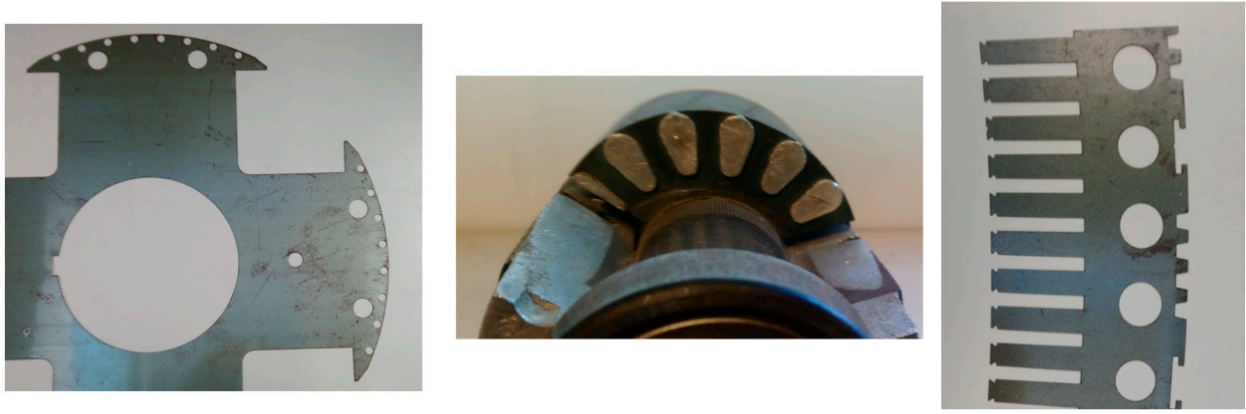

Figure 4. Example of sheet metal with slot for bar conductor.

The use of a massive bar for the stator of medium-power motors has, until recently, been quite rare because of the difficulty to realize the heads of coils in the case of a distributed winding with a diametral pitch. The originality of our bar winding lies in the conception of a technique of realization of coil heads, based on short bars, bent and alternated over and in front in the case of a rectangular bar [17,18].

\subsection{Additional Losses in the Bar}

In our laboratory, we designed and used solid-bar windings for electric-vehicle applications for the automotive and aerospace industries, the shape of its slots was rectangular [12,19]. First, we briefly describe the additional losses encountered on these slots. This problem has been treated for the study of alternator bars and rotors with bars of asynchronous machines [20-25]. These calculations are also useful for the optimization of copper losses in HF magnetic components more frequently subjected to the influence of frequency $[26,27]$.

The resistance of the associated copper conductor called "DC Resistance" $R_{D C}$ at zero frequency is generally expressed by the following relationship:

$$
R_{D C}=\rho_{C u} \cdot \frac{l_{\text {cond }}}{S_{u t i l e}}
$$

With the $\rho_{C u}$ resistivity of copper, $l_{\text {cond }}$ : length of the conductor, $S_{u t i l e}$ : the useful surface. 
Of course, the resistivity is temperature dependent such that the resistivity at temperature $\theta$ is:

$$
\rho_{\theta}=\rho_{20} \cdot[1+\alpha \cdot(\theta-20)]
$$

$\rho_{20}=1.72 \times 10^{-8} \Omega \mathrm{m}$ and $\alpha=0.004\left({ }^{\circ} \mathrm{C}\right)^{-1}$

The current i creates leakage flux in the conductor transverse to the slot, creating eddy currents $i_{f}$ in the conductor mass as shown in Figure 5.


Figure 5. Leakage flux in the bar. Eddy current $i_{\mathrm{f}}$.

These currents cause a non-uniform distribution of the current density J in the conductor (skin effect, backflow) as simulated in Figure 6.

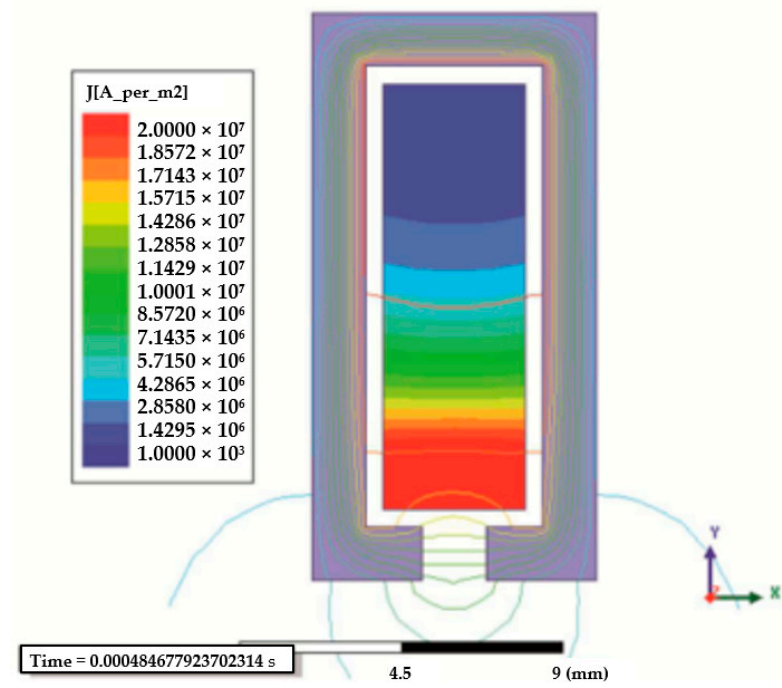

(a)

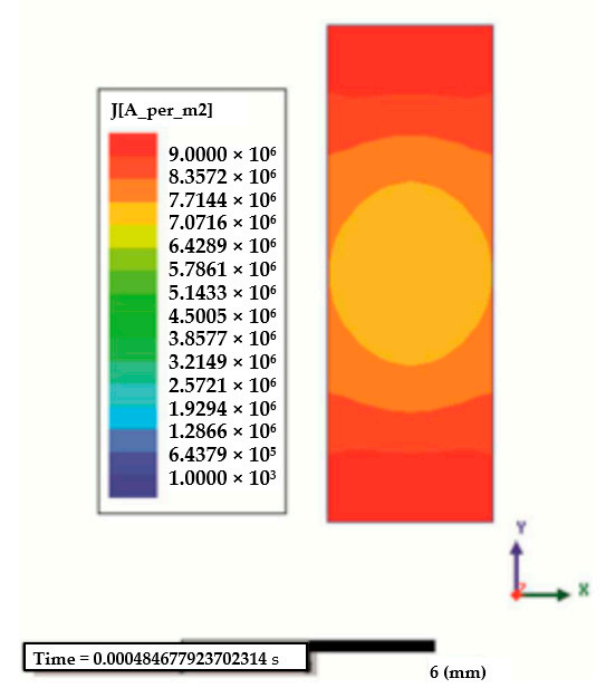

(b)

Figure 6. Current distribution in a bar excited with a sine current $\mathrm{f}=530 \mathrm{~Hz}$. (a) bar surrounded by a magnetic circuit $(\mathbf{b})$ bar in air.

Let us consider a slot where the height of copper $h_{c u}$ is subdivided into elementary strands isolated from each other, and we neglect the thicknesses of insulating material with respect to those of the copper. The evolution of the magnetic field $\mathrm{H}$ is linear as a function of $y$ as shown in Figure 7. 


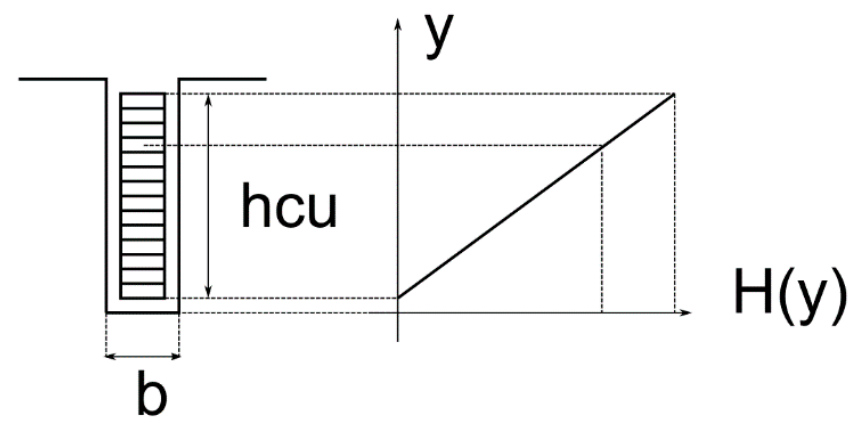

Figure 7. $\mathrm{H}$ fields in the bar.

The resulting flux from $\mathrm{H}$ acts on this section and induces an e.m.f. in the conductor. This induces currents which modify the total current distribution in the slot and thus its current density. It is easy to show that this current density $\mathrm{J}$ is higher near the air gap if we consider J0 as the current density in the case of a homogeneous distribution ( $\mathrm{f}=0 \mathrm{~Hz})$. We have for example the distribution of the current density schematized on Figure 8 in the case of a single conductor or that of two superimposed conductors. J0 represents the current density in the case of a uniform distribution [15].

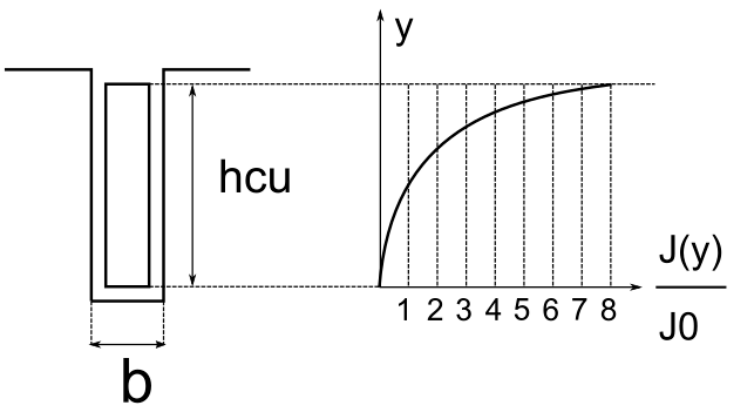

(a)

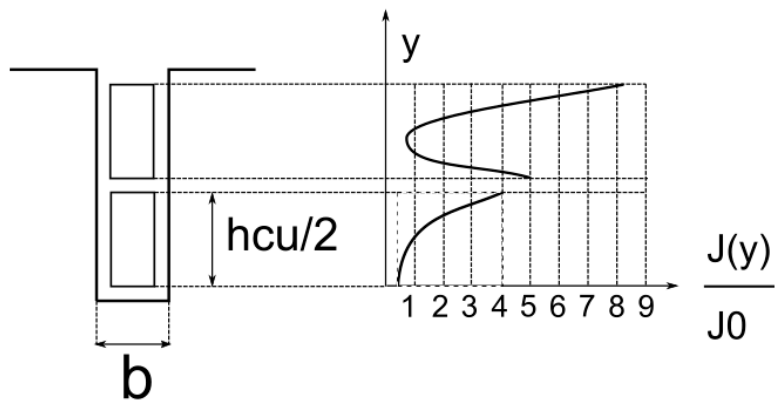

(b)

Figure 8. Current density J in the bar (a) single bar (b) two superimposed bar.

The total Joule losses can be expressed in a general by the expression (5):

$$
P_{A C}=\left(R+R_{S}\right) \cdot I^{2}=K \cdot R_{D C} \cdot I^{2}=K \cdot P_{D C}
$$

With $R_{S}$ fictive resistance corresponding to the additional losses and $K$ coefficient of higher than 1.

For Equation (5) $P_{A C}$ is the total Joule losses including additional losses and $P_{D C}$ is the DC Joule Losses.

The calculation of $K$ was first performed by Field, then Emde, Rogowski, Roth, Dreyfus and others [28-39]. The main results of his work are presented below.

The additional losses in a conductor increase with the height of the conductor, and we can reduce these losses by decreasing this height via a subdivision of the conductor. In the general case presented in Figure 9, we have a slot with adjacent conductors. 




Figure 9. Description of the slot.

In Figure 9 we have the following dimensions:

$b_{\text {enc }}$ : slot width;

$b_{c u}$ : total copper width of the conductors (if m conductor $b_{c u}=\mathrm{m} .1_{\mathrm{cu}}$ );

$h_{c u}$ : copper thickness of the elementary conductor;

$h_{\text {cut }}$ : thickness of an elementary insulated conductor;

$n$ : rank of conductor.

The study made on the alternator bars and from Maxwell's Equations allows us to define the expression of the penetration depth, which is given by Equation (6).

$$
\delta=\frac{1}{2 \pi} \sqrt{\frac{b_{e n c}}{b_{c u}} \cdot \frac{h_{c u}}{h_{c u t}} \cdot \frac{\rho_{\theta}}{f} \cdot 10^{7}}
$$

With:

$\rho_{\theta}$ : resistivity of copper at the considered temperature;

$f$ : frequency of the current in $\mathrm{Hz}$.

To express the coefficient $K$ we use a dimensionless parameter called "reduced height" which is given by the expression (7):

$$
\xi=\frac{h_{c u}}{\delta}=2 \pi \cdot h_{c u} \sqrt{\frac{b_{c u}}{b_{e n c}} \cdot \frac{h_{c u t}}{h_{c u}} \cdot \frac{f}{\rho_{\theta}} \cdot 10^{-7}}
$$

The additional losses depend on the rank of the conductor in the slot. Several possibilities are present, such that either each conductor is crossed by the same current $I$ or there can be different currents.

In the case where we have $\mathrm{n}$ layers of conductors as in Figure 9, for a conductor of rank $n$, the value of $K_{n}$ can be expressed by the relation (8) [28,39].

$$
K_{n}=\varphi(\xi)+\left[\left(\frac{I_{e}}{I_{n}}\right)^{2}+\left(\frac{I_{e}}{I_{n}}\right) \cdot \cos \left(\varphi_{n}\right)\right] \cdot \psi(\xi)
$$

where $n$ as the rank of the conductor, $I_{n}$ is the current flowing through conductor in row $n$ and $\varphi_{n}$ the phase shift between $I_{n}$ and $I_{e} \varphi_{n}=\left(\overrightarrow{I_{e}}, \overrightarrow{I_{n}}\right)$.

$I_{e}$ is the geometrical sum of the currents flowing in all the $(n-1)$ conductors below $n$ expressed by the relation (9).

$$
I_{e}=\sum_{n=1}^{n-1} I_{n}
$$

The two functions $\varphi(\xi)$ and $\psi(\xi)$ are equivalent to corrective functions according to the phenomena encountered. The $\varphi(\xi)$ function represents the impact of the skin effect and 
effect of backflow, and the $\psi(\xi)$ function represents the proximity effects in the presence of other conductors.

By defining the functions $\varphi(\xi)$ and $\psi(\xi)$ by Equations (10) and (11).

$$
\varphi(\xi)=\xi \cdot \frac{\sinh (2 \xi)+\sin (2 \xi)}{\cosh (2 \xi)-\cos (2 \xi)}
$$

And

$$
\psi(\xi)=2 \xi \cdot \frac{\sinh (\xi)-\sin (\xi)}{\cosh (\xi)+\cos (\xi)}
$$

On Figure 10 we see the evolution of the two curves $\varphi(\xi)$ and $\psi(\xi)$.

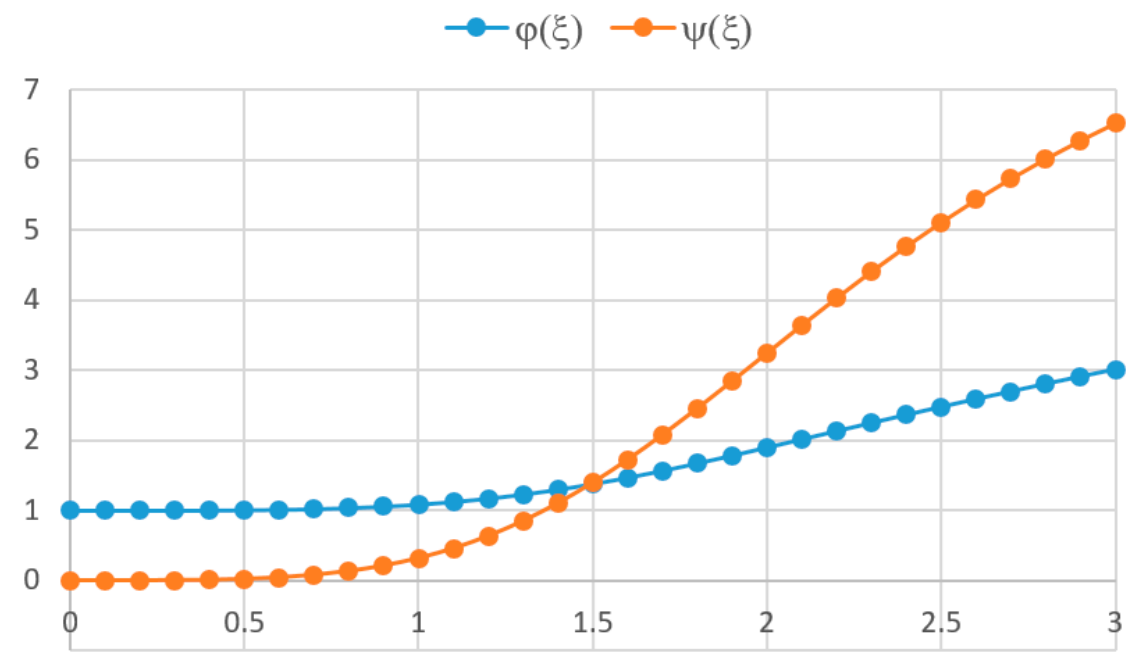

Figure 10. Evolution of the two curves $\varphi(\xi)$ and $\psi(\xi)$.

In general, we can calculate the $K_{n}$ coefficient for each layer. The total losses are thus equal to:

$$
P_{A C}=\sum_{n} K_{n} \cdot R_{D C n} \cdot I_{n}^{2}
$$

In the case where the currents in all conductors are identical and in phase, we have a simplification of the expression of $K$ as Equation (13).

$$
K_{n}=\varphi(\xi)+n \cdot(n-1) \cdot \psi(\xi)
$$

It is possible to calculate the average coefficient $K_{m}$ by summing the $\mathrm{n}$ layers we have, then using the following expression:

$$
K_{m}=\frac{1}{n} \sum_{k=1}^{n}[\varphi(\xi)+k \cdot(k-1) \cdot \psi(\xi)]=\varphi(\xi)+\frac{\left(n^{2}-1\right)}{3} \cdot \psi(\xi)
$$

In the case where $0 \leq \xi \leq 1$ we have a good approximation for the coefficient $K$, given by the expression (15).

$$
K \approx 1+\frac{n^{2}-0.2}{9} \cdot \xi^{4}
$$

For the case where there is only one rectangular conductor per slot, we have the following simplifications.

$$
\xi=\frac{h_{c u}}{\delta}=2 \pi \cdot h_{c u} \sqrt{\frac{b_{c u}}{b_{e n c}} \cdot \frac{f}{\rho_{\theta}} \cdot 10^{-7}}
$$


And

$$
K=K_{m}=\varphi(\xi)=1+\frac{4}{45} \xi^{4}
$$

Each bar winding has the lowest resistance in the alternating current for a certain height of conductor, called the critical height. The critical height corresponds to the useful section in which the current flows, so it is unnecessary to go beyond this critical height, because if it is exceeded, the losses tend to remain constant. On the other hand, if we are below the critical height, the losses increase because the current density increases in the conductor. The total losses therefore pass through a minimum for the critical height.

In our case, the expression of the total losses is given by Equation (18).

$$
P_{A C}=K \cdot P_{D C}=\xi \cdot \frac{\sinh (2 \xi)+\sin (2 \xi)}{\cosh (2 \xi)-\cos (2 \xi)} \cdot P_{D C}
$$

Or again

$$
R_{A C}=K \cdot R_{D C}=\xi \cdot \frac{\sinh (2 \xi)+\sin (2 \xi)}{\cosh (2 \xi)-\cos (2 \xi)} \cdot R_{D C}
$$

This power must be minimal for the value of the critical height $h_{c r i t}$, that is to say that $d P_{A C} / d \xi=0$. After calculation, we obtain $\xi_{h c r i t}=1.57$. The optimal coefficient $K$ is thus equal to:

$$
K_{\text {Rop }}=\varphi\left(\xi_{\text {hcrit }}\right)=1.44
$$

The critical height can be estimated by the relation (21).

$$
h_{\text {crit }}=\frac{1.44}{2 \pi \sqrt{\frac{b_{c u}}{b_{e n c}} \cdot \frac{f}{\rho_{\theta}} \cdot 10^{-7}}}
$$

For our electric boat propulsion application, instead of using rectangular or square bars, we opted for cylindrical bars as shown in Figure 11. In this configuration, we have one bar per slot.

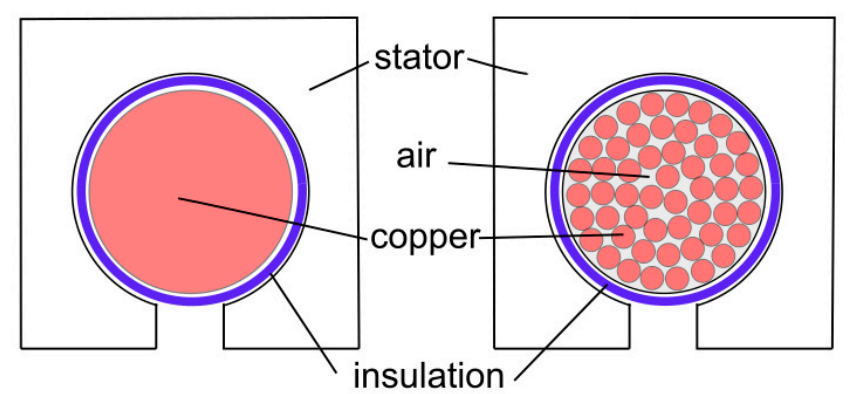

Figure 11. Illustration of slot filling for a solid conductor versus round conductors.

Let us recall the advantages of this type of bar for the design of windings:

- High filling rate ( $80 \%$ filling instead of $30 \%)$;

- Reduced iron-copper thermal resistance;

- The slot can be very closed;

- Very compact coil heads;

- $\quad$ Simplified winding design, robustness and reliability.

This type of bar does not need to be machined because we use standard dimensions. We do not have to calculate the critical height in this type of bar as in the case of rectangular bars.

As for the rectangular bars, these currents cause a non-uniform distribution of the current density $\mathrm{J}$ in the conductor (skin effect, backflow) as simulated in Figure 12. 


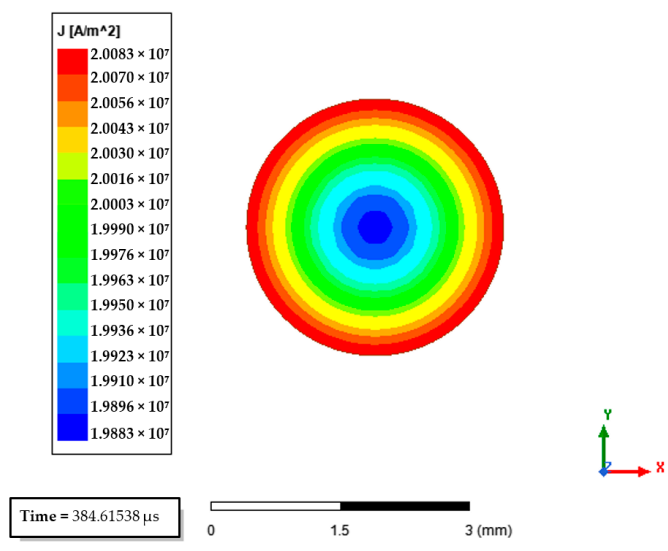

(a)

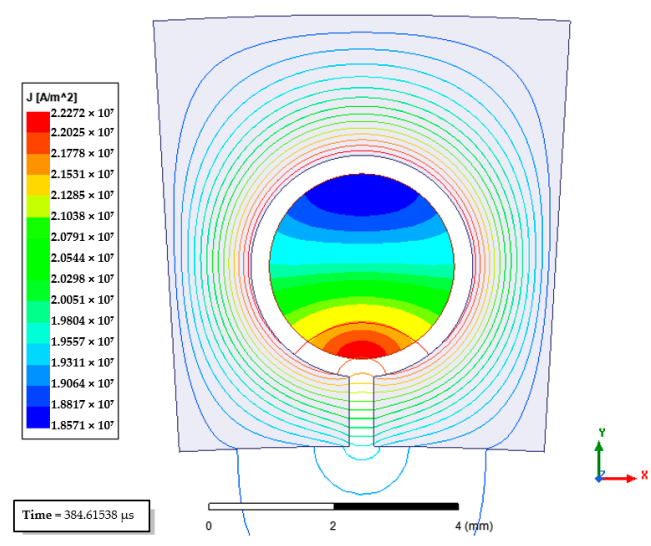

(b)

Figure 12. Current distribution in a circular bar excited with a sine current $f=650 \mathrm{~Hz}$. (a) bar in air (b) bar surrounded by a magnetic.

In the case of a round bar, the study conducted using Maxwell's equations allows us to define the expression of the penetration depth (skin thickness), which is given by the expression (22).

$$
\delta=\frac{1}{2 \pi} \sqrt{\frac{\rho_{\theta}}{f} \cdot 10^{7}}
$$

In the simplified case of a cylindrical conductor in air the total loss coefficient $K$ is expressed using the relation (23) [40].

$$
K=\frac{R}{2 \delta} \cdot \frac{\operatorname{ber}\left(\frac{R}{\delta}\right) \cdot b e i^{\prime}\left(\frac{R}{\delta}\right)-b e i\left(\frac{R}{\delta}\right) \cdot b e r^{\prime}\left(\frac{R}{\delta}\right)}{\left(b e i^{\prime}\left(\frac{R}{\delta}\right)\right)^{2}+\left(b e r^{\prime}\left(\frac{R}{\delta}\right)\right)^{2}}
$$

This expression is defined by using the functions of Kelvin-Bessel [41].

In the case where there is a proximity effect due to other conductors we have the relation $(24)[39,40]$.

$$
K=\frac{R}{2 \delta} \cdot\left[\frac{\operatorname{ber}\left(\frac{R}{\delta}\right) \cdot \operatorname{ber}^{\prime}\left(\frac{R}{\delta}\right)-\operatorname{bei}\left(\frac{R}{\delta}\right) \cdot \operatorname{bei}^{\prime}\left(\frac{R}{\delta}\right)}{\left(\operatorname{bei}^{\prime}\left(\frac{R}{\delta}\right)\right)^{2}+\left(\operatorname{ber}^{\prime}\left(\frac{R}{\delta}\right)\right)^{2}}-2 \pi \cdot(2 m-1)^{2} \cdot \frac{\operatorname{ber}_{2}\left(\frac{R}{\delta}\right) \cdot \operatorname{ber}_{2}\left(\frac{R}{\delta}\right)+\text { bei }_{2}\left(\frac{R}{\delta}\right) \cdot \text { ber }_{2}\left(\frac{R}{\delta}\right)}{\left(b e i\left(\frac{R}{\delta}\right)\right)^{2}+\left(b e r\left(\frac{R}{\delta}\right)\right)^{2}}\right]
$$

With $b e r_{2}$ and $b e i_{2}$ functions of Kelvin-Bessel order 2 and m number of conductors.

The second term of the equation represents the effect of proximity of $m$ conductors but can also be assimilated to the effect of an external electric field. In our analysis, we can also consider the effect of a perturbation of the field lines due to the slot opening.

In our case, the slot opening as shown in Figure 13, creates a disturbance of the field lines in the conductor and thus a modification of the current density as shown in Figure 12. 


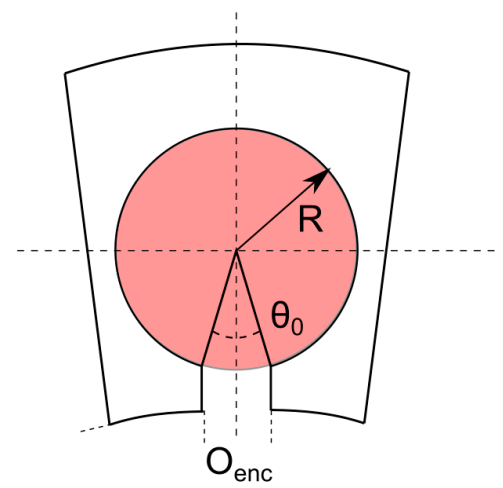

Figure 13. Analytical dimension of the slot opening.

In this case, we can express the ratio $K$ by the relation (25) defined by previous studies on the slot of the cage-rotor induction motor [42].

$$
K=\frac{R}{2 \delta} \cdot\left[\frac{\operatorname{ber}\left(\frac{R}{\delta}\right) \cdot \operatorname{bei}^{\prime}\left(\frac{R}{\delta}\right)-\operatorname{bei}\left(\frac{R}{\delta}\right) \cdot \operatorname{ber}^{\prime}\left(\frac{R}{\delta}\right)}{\left(b e i^{\prime}\left(\frac{R}{\delta}\right)\right)^{2}+\left(\operatorname{ber}^{\prime}\left(\frac{R}{\delta}\right)\right)^{2}}+2 \sum_{n=1}^{\infty} G_{n} \cdot \frac{\operatorname{ber}_{n}\left(\frac{R}{\delta}\right) \cdot \operatorname{bei}^{\prime}{ }_{n}\left(\frac{R}{\delta}\right)-\operatorname{bei}_{n}\left(\frac{R}{\delta}\right) \cdot \operatorname{ber}^{\prime}{ }_{n}\left(\frac{R}{\delta}\right)}{\left(\operatorname{bei}_{n}{ }_{n}\left(\frac{R}{\delta}\right)\right)^{2}+\left(\operatorname{ber}_{n}\left(\frac{R}{\delta}\right)\right)^{2}}\right]
$$

With $b e r_{n}$ and $b e i_{n}$ functions of Kelvin-Bessel order $n$, and the function $G_{n}$ defined by relation (26).

$$
G_{n}=\frac{\sin \left(\frac{1}{2} n \theta_{0}\right)}{\frac{1}{2} n \theta_{0}}
$$

The finite element method (FEM) with ANSYS Maxwell software was used to calculate the additional losses in the solid bar winding. The Field effect depends on two parameters the frequency of the current flowing through the solid bars and the diameter of the bar, so simulations were performed to check the effect of each parameter on the coefficient of the additional losses. Figure 14a,b show the comparison of the different analytical expressions with the finite element calculations. We have calculated relations (23) and (24) with $m=1$ and relation (25) for different orders. The objective is to find an analytical model close to the finite element calculations.

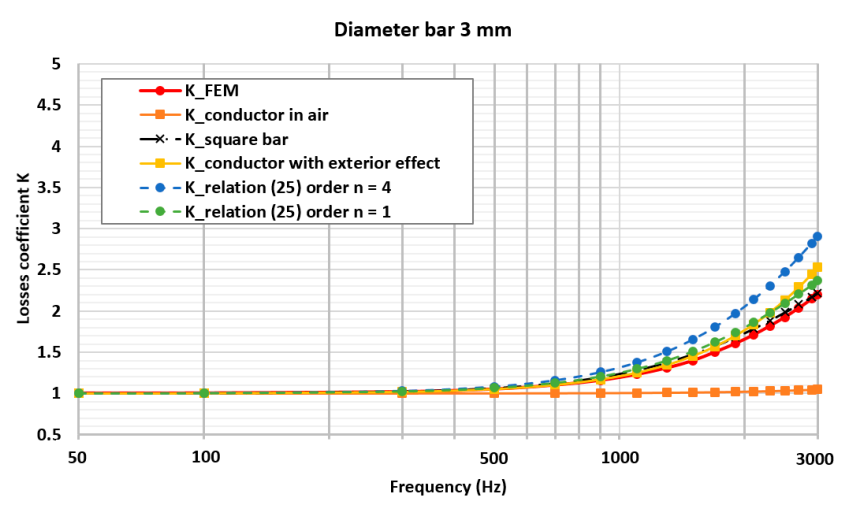

(a)

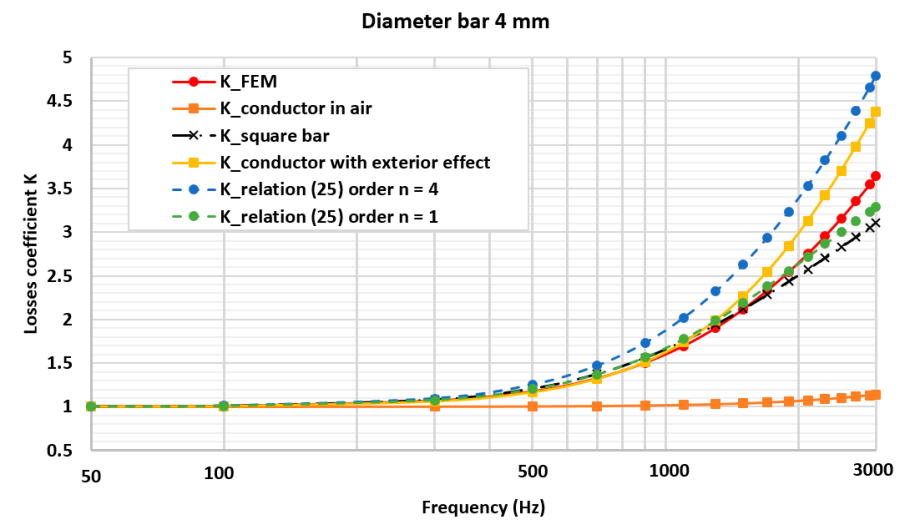

(b)

Figure 14. Losses coefficient as a function of frequency (a) $R=1.5 \mathrm{~mm},(\mathbf{b}) \mathrm{R}=2 \mathrm{~mm}$.

In the analytical models, we also calculated the coefficient $K$ for a square bar. In order to do this, we used the side of the square equal to the diameter of the bar and we used the relations (6) and (16). 
The slot opening is constant in our simulations $\theta_{\mathrm{enc}}=0.4 \mathrm{~mm}$. For a bar of diameter $3 \mathrm{~mm}$, we had an angle of $12.86^{\circ}$, and for a bar of $4 \mathrm{~mm}$ we had an angle of $9.97^{\circ}$.

The results obtained for a bar of diameter $3 \mathrm{~mm}$ and $4 \mathrm{~mm}$ are presented in Figure 14 .

In Figure 14, the different models give an analytical value of the coefficient $K$ by excess. The three analytical models (relation (24) with $m=1$, relation (25) for an order $n=1$ and the case of square bar) can be used for this bar up to a frequency of $1000 \mathrm{~Hz}$. In Figure 14a,b the additional loss coefficient increases with the diameter of the bar.

We studied the additional losses due to the currents in the solid bars, but we also needed to account for the influence of the field produced by the magnets. This case is presented during the finite element simulation of the motor in the next chapter.

The previous study showed that the compared analytical models can be introduced by optimization or analytical-sizing methods for permanent magnet-synchronous motors. We compare our analytical, simulation and prototype test results in the next chapter.

\subsection{Winding Overhang for the Bar Winding}

In the design of our solid-bar windings, we used optimized dental and distributed windings. For each winding, we had to innovate the design of the winding overhang to reduce their location and associated losses as much as possible [14,15].

In Figure 15, we have an overview of the classic wire coil heads and a solid-bar winding overhang.

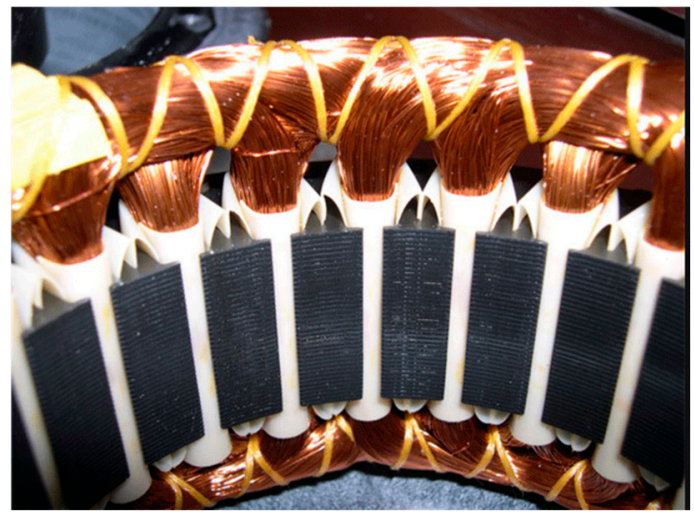

(a)

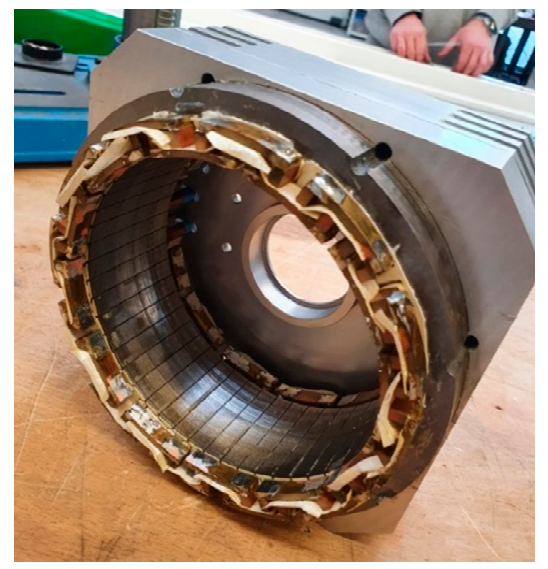

(b)

Figure 15. Winding detail with highlighting of the winding overhang: (a) Wire winding, (b) Solid-bar winding.

The additional losses for the winding overhang only take into account the skin effect. In this case, we can use the relation (27) expressed by Levasseur applicable to conductors of which the section has any form [43].

$$
K_{\text {head }}=\sqrt[6]{0.17798+\left(\frac{2 \pi \cdot S \cdot \sqrt{\mu c f}}{\rho_{\theta}}\right)^{6}}+0.25
$$

It is sufficient to determine the steady-state losses analytically and to use the additional loss factor

\section{Application-Prototype}

\subsection{Motor Characteristics}

Our study realized an electric boat motor of POD configuration. The use of a nacelle propulsion system, called POD, facilitates for the housing of the electric propulsion motor, which was previously integrated in the hull of the vessel. This makes it possible to incorporate the steering gear, the propeller, the propulsion motor, the shaft line, etc., in a single 
unit the rudder as shown in Figure 16a,b [44]. The podded propulsion system is a modern ship propulsion concept.

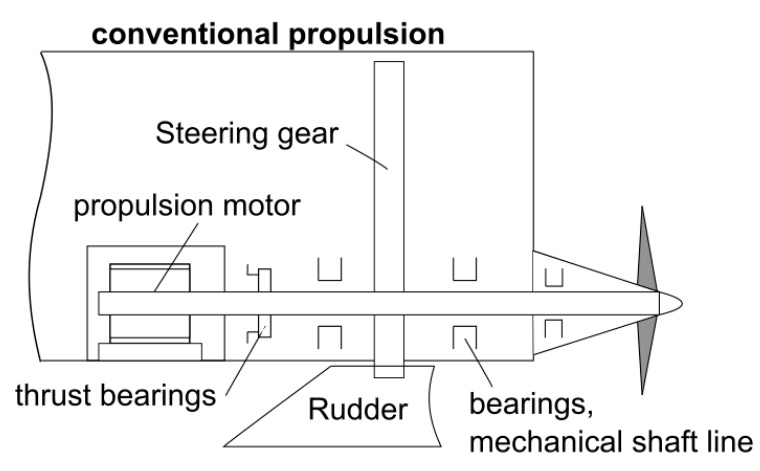

(a)

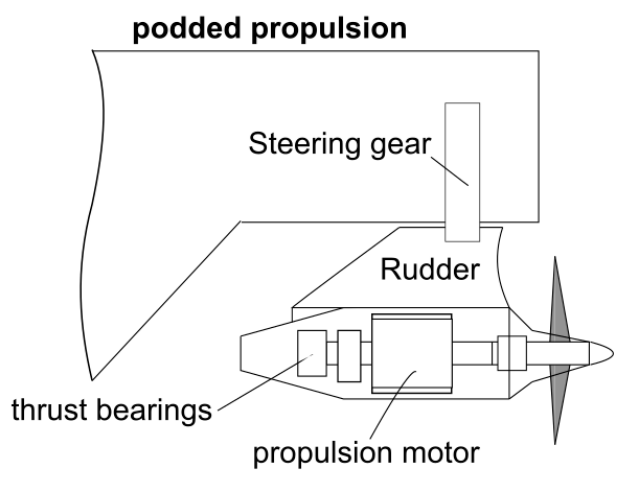

(b)

Figure 16. Propulsion system: (a) conventional propulsion, (b) POD propulsion.

The advantages for this type of motorization are:

- Improved energy efficiency;

- Flexible design capability;

- Reduced internal volume;

- Excellent maneuverability;

- Significant reduction in the size and weight of the machinery on board the boat;

- Use of the thruster as a rudder;

- Simplification of the propeller machine linkage.

We present a podded propulsion system in Figure 17.

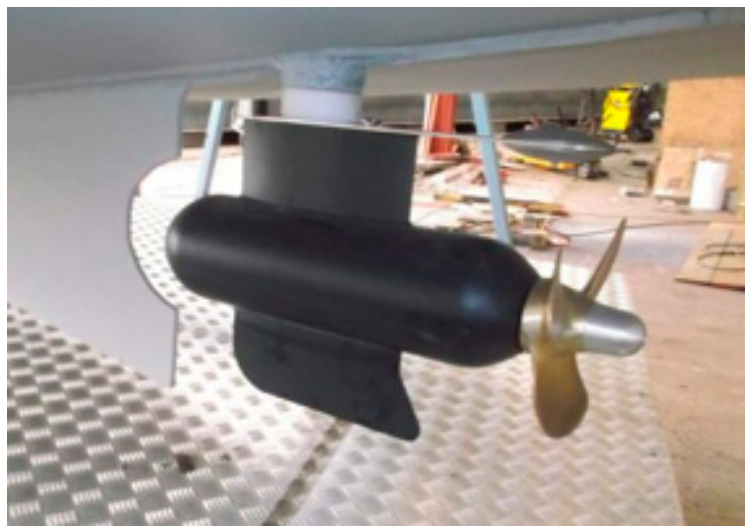

(a)

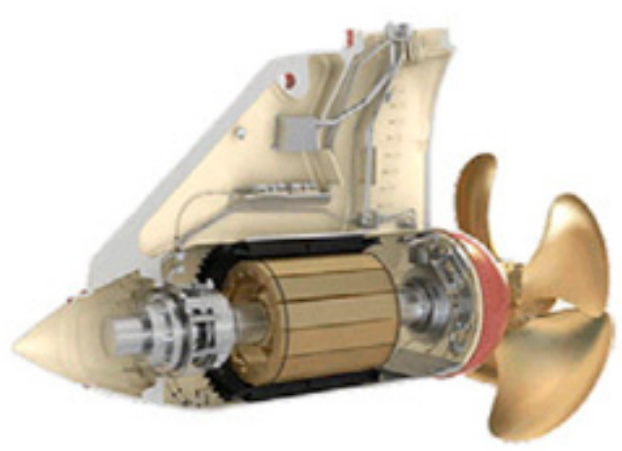

(b)

Figure 17. Example of Podded propulsion system: (a) POD view, (b) Motor view.

The specifications for this application is a motor with a power $\mathrm{P}=4.5 \mathrm{~kW}$ for a speed of $1500 \mathrm{rpm}$ with a direct drive. This power is imposed by the French legislation with respect to the legal limit of a boat license. The speed of rotation of the propeller is fixed by the manufacturer of the boat, we do not have mechanical gearbox and the speed of rotation of the motor is that of the propeller. With regard to these powers, the propeller is about $20 \mathrm{~cm}$ in diameter, so the motor body, placed in front of the propeller, should not be more than $12 \mathrm{~cm}$ in diameter, and the length of the motor is less important. The motor is in the water, so it benefits from effective cooling so the losses are not critical, but in order not to penalize the autonomy, it is necessary to obtain an output of about $90 \%$. The supply voltage is $60 \mathrm{~V}$. 
The permanent magnet synchronous motor is a three-phase synchronous machine with surface mounted magnets. The choice of materials for the stator and rotor yokes is made of magnetic sheets FeSi M270-35A of $0.35 \mathrm{~mm}$ thickness.

The magnets are $\mathrm{NdFeB}$ (Neodymium-Iron-Boron), with a remanent induction $\mathrm{Br}=1.26 \mathrm{~T}$ and a coercive field $\mathrm{Hc}=-912,000 \mathrm{~A} / \mathrm{m}$

Following the specifications, the determined motor has the dimensions presented in Table 1.

Table 1. Motor specification.

\begin{tabular}{lcc}
\hline \multicolumn{1}{c}{ Designation } & Numerical Value & Units \\
\hline Outer diameter $D_{e}$ & 110 & $\mathrm{~mm}$ \\
Length motor $L_{z}$ & 150 & $\mathrm{~mm}$ \\
Air gap $e$ & 1 & $\mathrm{~mm}$ \\
Air gap radius $R_{e}$ & 48 & $\mathrm{~mm}$ \\
Height of stator yoke $h_{c s}$ & 2.24 & $\mathrm{~mm}$ \\
Bar diameter $d_{b}$ & 3 & $\mathrm{~mm}$ \\
Slot diameter $d_{e n c}$ & 3.6 & $\mathrm{~mm}$ \\
Slot opening $o_{e n c}$ & 0.4 & $\mathrm{~mm}$ \\
Tooth-tip height & 1.16 & $\mathrm{~mm}$ \\
Magnet height & 4.5 & $\mathrm{~mm}$ \\
Magnet width & 4.84 & $\mathrm{~mm}$ \\
Height of rotor yoke & 3 & $\mathrm{~mm}$ \\
\hline
\end{tabular}

The bar winding with the dental pitch (by group) used in our motor consists of the grouping of the slots of a phase on a group of 120 degrees $[17,18]$. This winding is shown in Figure 17a, the view of the cylindrical bar winding is shown in Figure 18b. To ensure a phase shift between the electrical quantities of 120 degrees we modify the angle $\delta_{p h}$ of a tooth between two groups, this tooth called phase shift tooth. $\delta_{p h}$ and $\tau_{u}$ which is the pitch tooth is presented on Figure 18a.

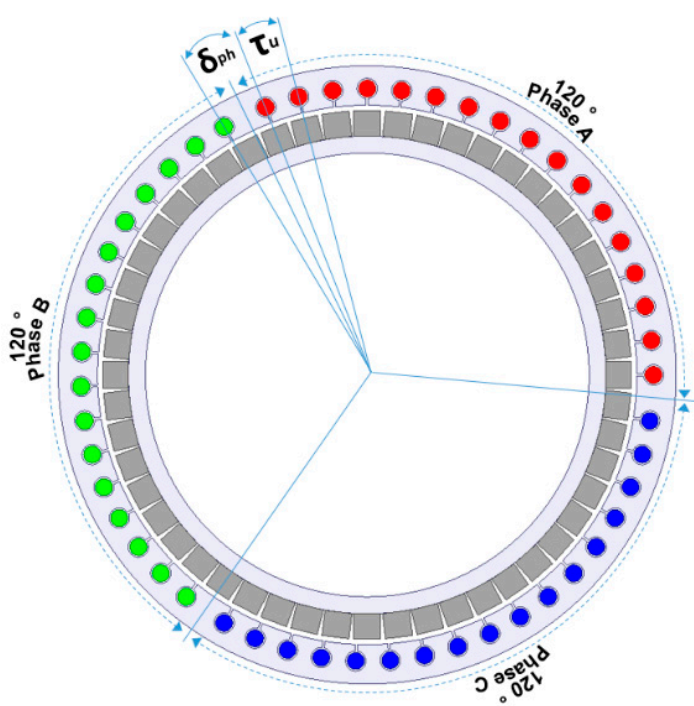

(a)

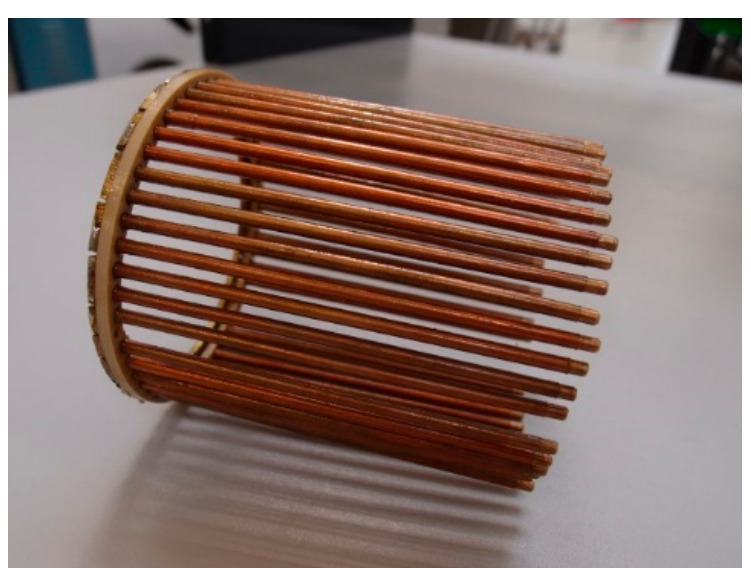

(b)

Figure 18. Description of motor: (a) Dental winding by group, (b) Winding view.

To reduce the mass of the motor, we increased the operating frequency so the number of poles of the motor would increase. The increase in frequency imposes a constraint on the mechanical feasibility of tooth size. For this type of winding, we have two relationships, namely a relation between the number of slot $N_{S}$ and the number of magnet $N_{R}=2$.p and a relation for the dimension of the dephasing tooth $\delta_{p h}$ and the number of slot $N_{S}$. This 
system of this equation is given by the system of Equation (28). In this configuration of winding $N_{S}$ must be a multiple of 3 [17].

$$
\left\{\begin{array}{c}
N_{R}=N_{S} \pm 1 \\
\delta_{p h}=\left[\frac{2 \pi-\frac{2 \pi}{N_{R}}\left(N_{S}-n\right)}{n}\right]
\end{array}\right.
$$

With $n$ number of slot groups per phase equal to 3 or 6 .

The torque and the e.m.f of the motor depends on the number of slots $N_{S}$. For our application with $n=3$ (as show in Figure 18a) we obtain a number of slots equal to $N_{S}=51$. For our configuration the choice of $N_{R}=N_{S}+1=52$ is related to the dimension of the phase shift tooth. Indeed, there is a risk of saturation of this tooth in the case where $N_{R}=50$.

The rotor construction is a classic realization whereby the magnets are pasted to the surface and segmented along the motor length (for our prototype we have 3 magnets). The rotor does not have a sleeve. We show, in Figure 19, the photos of the stator and the rotor for another prototype of the same design but of a smaller size.

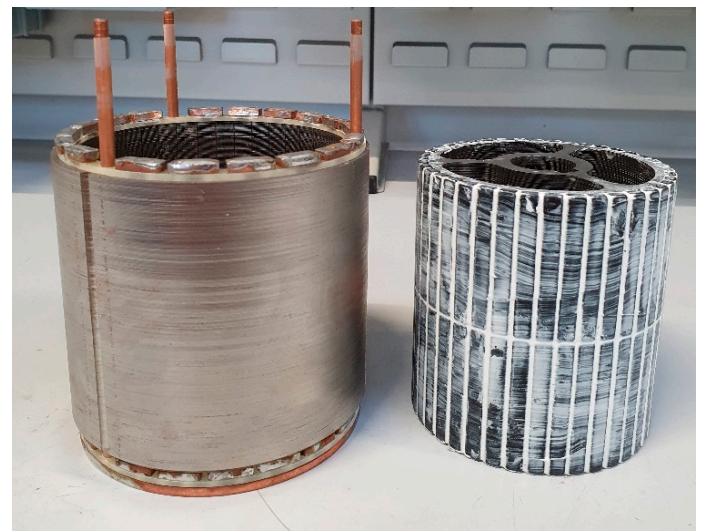

Figure 19. Picture of stator and rotor.

In Figure 20, we have a representation of the flux density B in the motor simulated by Ansys software for $I 1=142 \mathrm{~A}, I 2=-71 \mathrm{~A}, I 3=-71 \mathrm{~A}$ and $f=650 \mathrm{~Hz}$.

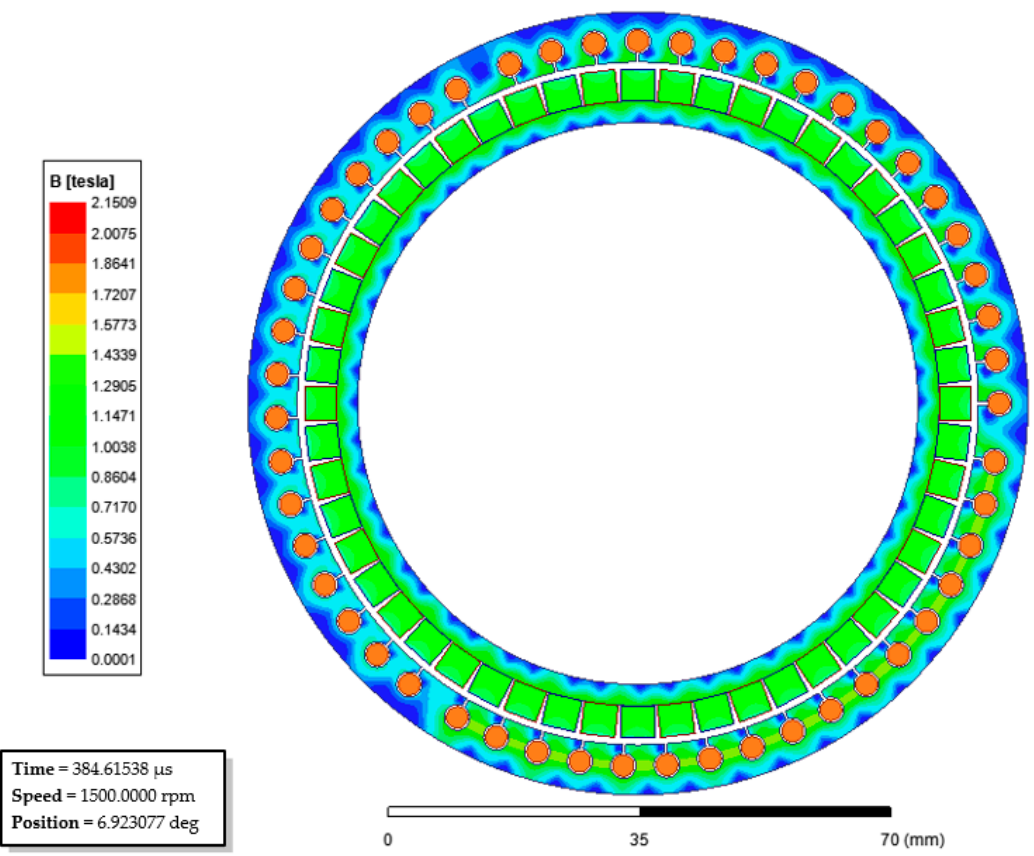

Figure 20. Flux density distribution in the active parts of the Motor. 
In Figure 21, we have a 3D representation of currents density in the winding simulated by Ansys software for RMS value $I=100 \mathrm{~A}$ and $f=650 \mathrm{~Hz}$.

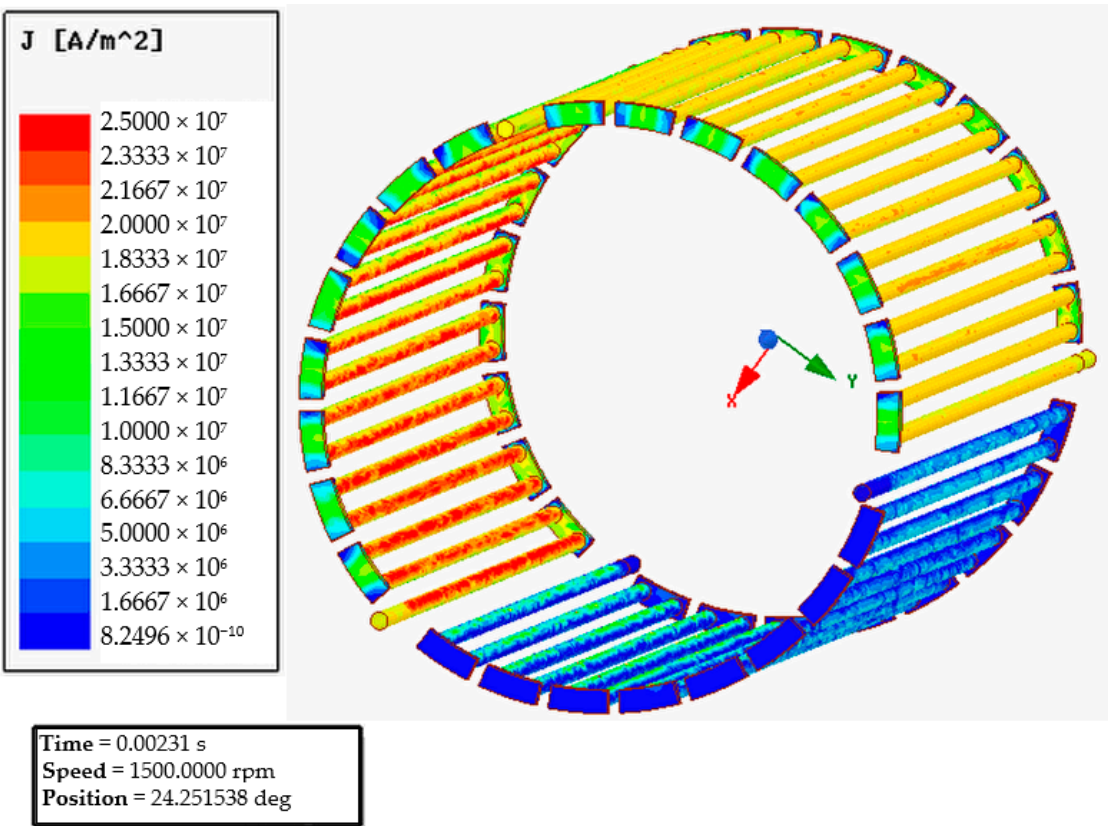

Figure 21. 3D Currents density distribution in the winding.

In Figure 22a, we have a view of the motor with the sealing flanges. For the realization of the tests we have designed a waterproof container with a shaft outlet of a reduced size to carry out the tests in an immersed operation as shown in the photo of Figure 22b.

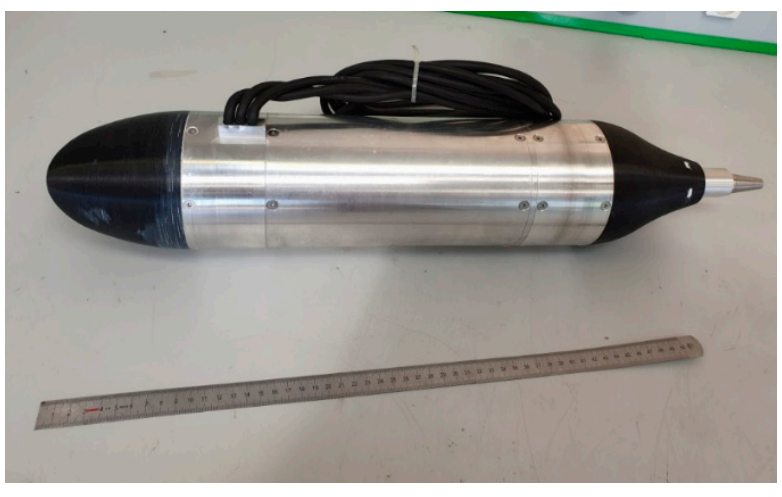

(a)

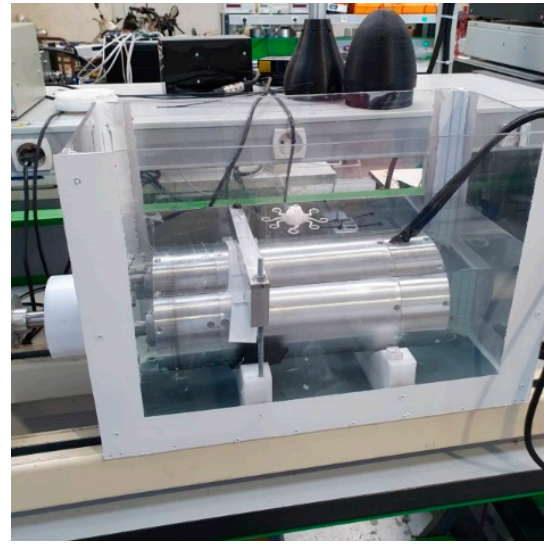

(b)

Figure 22. Prototype: (a) View of Motor with the sealing flanges, (b) Waterproof container.

\subsection{Measurement Bench}

The following diagram, in Figures 23 and 24, shows the different elements and measuring devices used to characterize and determine the efficiency of the motor.

The converter used is a commercial, low-voltage converter with sensorless vector control. 


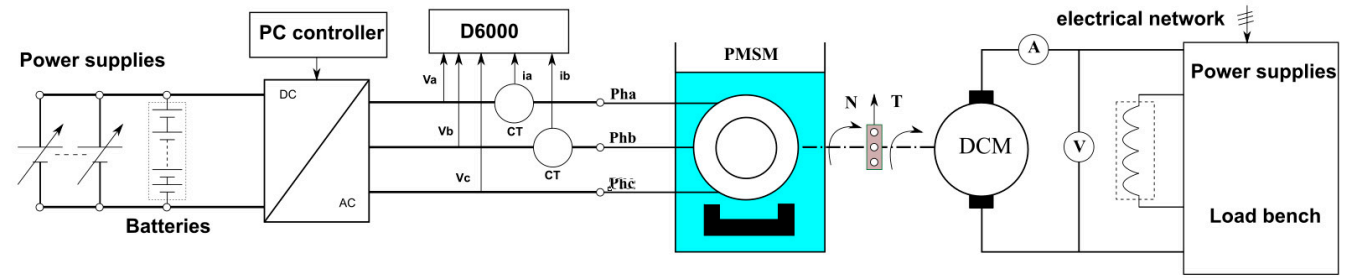

Figure 23. Experimental design.



Figure 24. Test Bench.

\subsection{Electrical and FEA Characterizations}

The equivalent electric model of the machine is a classic RLE model from BehnEschenburg, as shown in Figure 25.

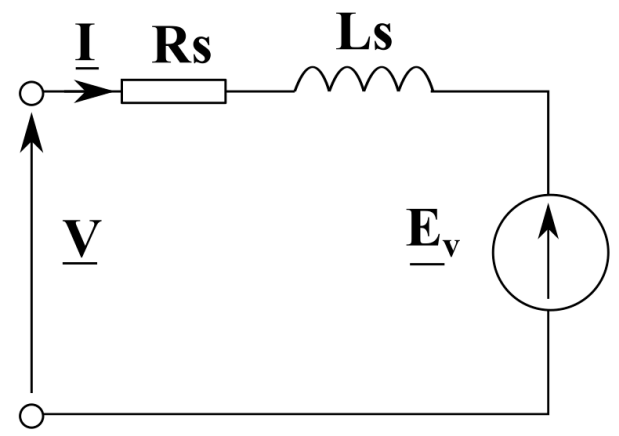

Figure 25. Electric model RLE.

The tests have allowed us to characterize the motor, and we present the results in Table 2. 
Table 2. Electric parameters.

\begin{tabular}{lccc}
\hline \multicolumn{1}{c}{ Designation } & Measurement & Simulation & Units \\
\hline Resistance of one phase and & 10.8 & 10.9 & $\mathrm{~m} \Omega$ \\
cable: $R_{s}+R_{\text {cable }}$ & 0.067 & 0.072 & V.s.rad $^{-1}$ \\
Constant of e.m.f.: $K_{e}$ & 0.18 & 0.21 & $\mathrm{Nm}^{-1}$ \\
Torque coefficient: $K_{T}$ & 16 & 16.4 & $\mathrm{mH}$ \\
Synchronous Inductance: $L_{s}$ & & &
\end{tabular}

In Figure 26, the pace of the measured line to the line of e.m.f. compared to the one obtained by FEA is presented. In Figure 27, we can see the harmonic spectrum of the measured e.m.f.

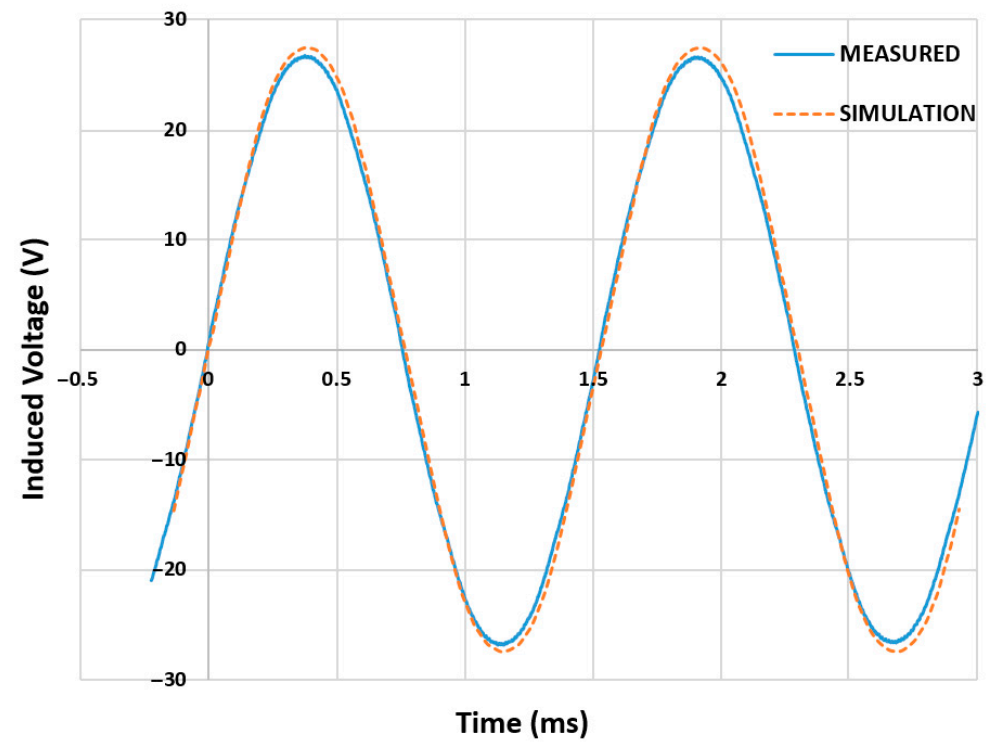

Figure 26. Measured and simulated line to line e.m.f.



Figure 27. Harmonic spectrum of the measured e.m.f.

The e.m.f. of our motor is perfectly sinusoidal. The experimental results verify the results deduced by simulation with the ANSYS software.

In Figure 28, the torque calculated by FEA with a torque ripple $\Delta \mathrm{T}=0.59 \mathrm{~N} \cdot \mathrm{m}$ is presented. 


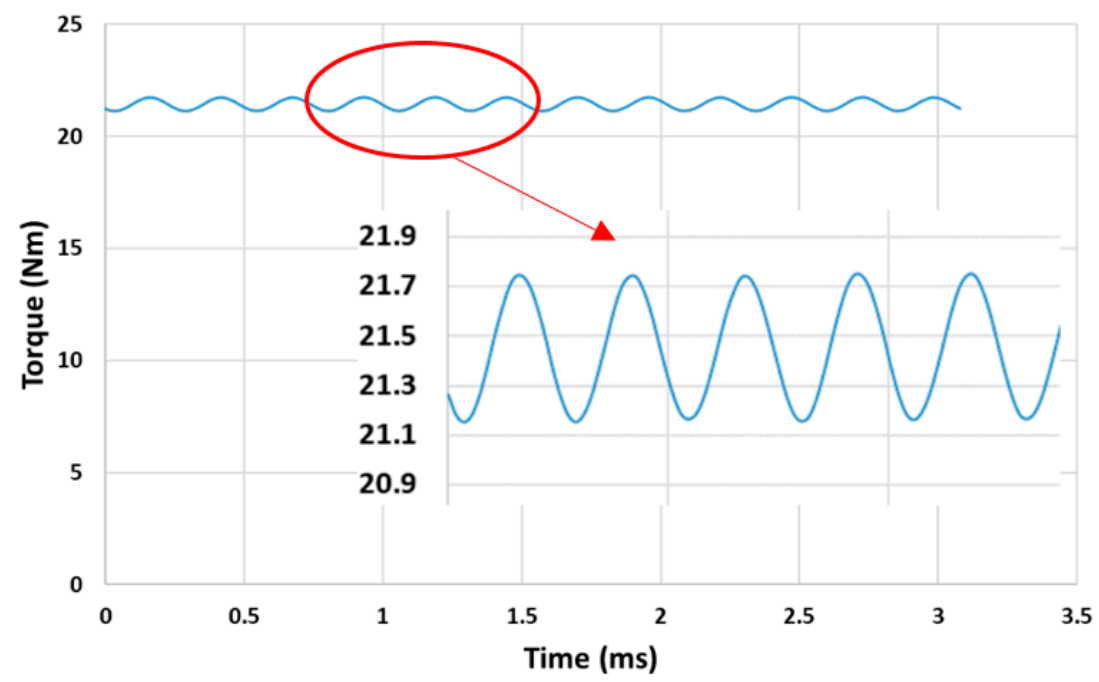

Figure 28. Torque and the torque ripple.

\subsection{Load Test}

The determination of the experimental efficiency was performed with the loss-separation method using Equation (29).

$$
\eta_{\text {electromagnetic }}=\frac{P_{D C M}+P_{J D C M}+P_{\text {mecatotal }}}{P_{\text {OUT INV }}-P_{\text {Jcable }}}
$$

With:

$P_{D C M}$ : Power delivered by the DC generator;

$P_{\text {JDCM }}$ : Joule losses in the DC generator;

$P_{\text {meca total }}$ : total mechanical Power losses;

Pout INV: Output Power from the Inverter;

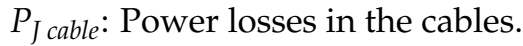

We have calculated the electromagnetic efficiency of our motor for different load and for different rotation speeds. In Figure 29, we can see the shape of the characteristics.

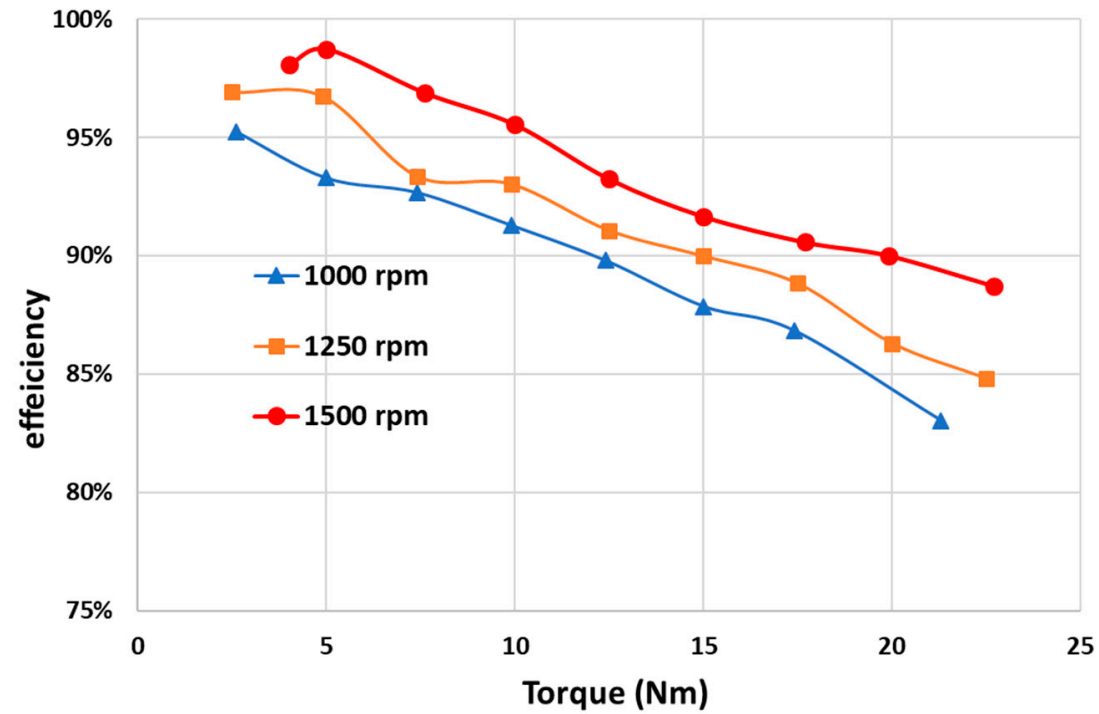

Figure 29. Efficiency curve vs. torque for different rotational speed.

The efficiency decreases with the increase in the torque, which corresponds to an increase in the current and thus of the Joule losses. 
Table 3 shows the values of the additional loss coefficient $\mathrm{K}$ calculated using simulation, an analytical model and experimentally.

Table 3. Comparison of the coefficient $\mathrm{K}$.

\begin{tabular}{rccccc}
\hline Speed/Frequency & K Measured & K_Ext & K_Square & K_n = 1 & K FEM \\
\hline $1000 \mathrm{rpm} / 433 \mathrm{~Hz}$ & 1.30 & 1.06 & 1.07 & 1.06 & 1.04 \\
$1250 \mathrm{rpm} / 542 \mathrm{~Hz}$ & 1.12 & 1.09 & 1.10 & 1.09 & 1.06 \\
$1500 \mathrm{rpm} / 650 \mathrm{~Hz}$ & 1.21 & 1.10 & 1.12 & 1.17 & 1.09 \\
\hline
\end{tabular}

The values of the additional loss coefficient given by the analytical models are very similar to the finite element calculations, and the models studied are valid for a frequency below $1000 \mathrm{~Hz}$. To estimate the experimental loss coefficient, we determined, by FEM, the iron losses of our prototype because it is difficult to determine them experimentally even by the method of separate losses. This may explain the discrepancy of this coefficient between the experimental coefficient and the other values.

\section{Parametric Influences}

In this Section, we present the variables that have an influence on the performance of the motor. These variables are located at the level of the slot dimensions and include the slot-opening width $\left(O_{\text {enc }}\right)$, tooth-tip height $\left(h_{i s t h m}\right)$, thickness of the stator yoke $\left(h_{c s}\right)$. This study was conducted after the realization of the first prototype whose first objective was to show the feasibility of a motor with a cylindrical bar winding. We recall, in Figure 30, the names of the geometric dimensions of the stator.

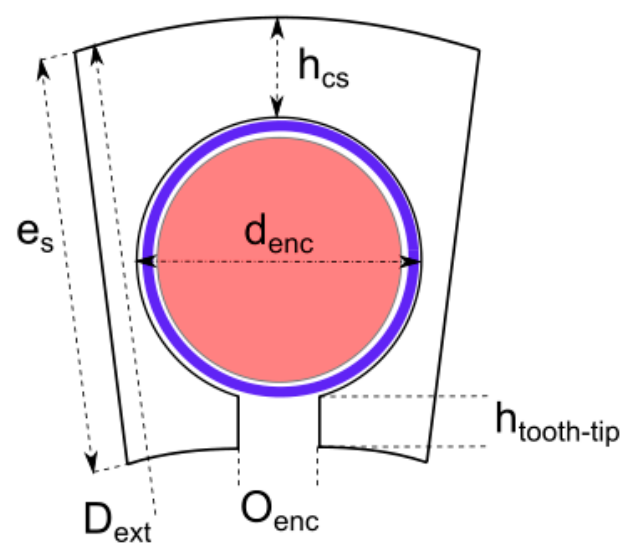

Figure 30. Dimension of the slot.

\subsection{Study of Stator Yoke}

The use of solid-bar winding allows us to dispense with the constraints on the slot opening, and it can be almost completely closed so we can optimize the slot-opening width with respect to the torque obtained. Figure 31 shows the simulation results obtained for the optimization of the slot-opening width with sinusoidal supply currents of 100 A RMS. 




Figure 31. FEA results of the optimization of slot opening width $\left(O_{\text {enc }}\right)$.

The torque had a maximum value for a slot opening between 0.4 and $0.5 \mathrm{~mm}$.

The slot-opening width also plays a role in the additional losses in solid-bar windings, through the losses caused by the rotation of the magnets where it acts as a barrier protecting the bars from the flux lines passing through the magnets as shown in the simulation results presented in Figure 32. For these calculations, the supply currents were fixed at 100 A RMS.

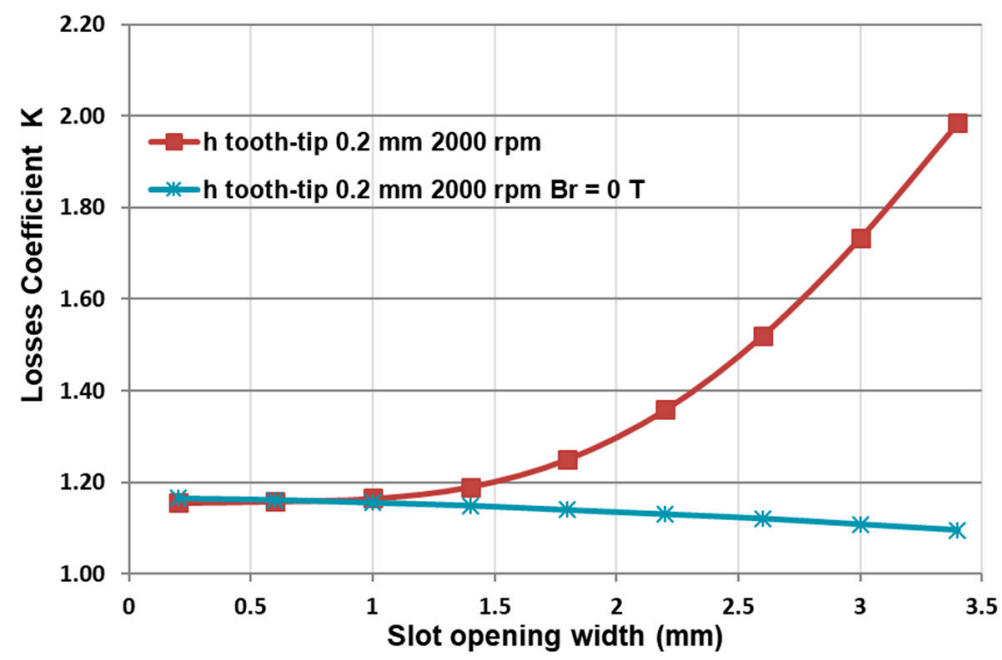

Figure 32. Slot opening width effect on Losses Coefficient $K$.

In Figure 32, the curve for an induction of $\mathrm{Br}=0 \mathrm{~T}$ (the blue curve) shows the fringe effect where the larger the slot opening, the lower the additional losses (diminution of the $K$ coefficient). The wider the slot opening, the more the magnets produce additional losses.

In a further study of the effect of the slot opening on the additional losses in the windings, the calculations provided in Figure 33 show that the greater the height of the slot opening, the less the loss coefficient increases rapidly. It is noted that the losses caused by the field of the magnets can be avoided (or even cancelled) by choosing a slot opening of less than $1 \mathrm{~mm}$. 


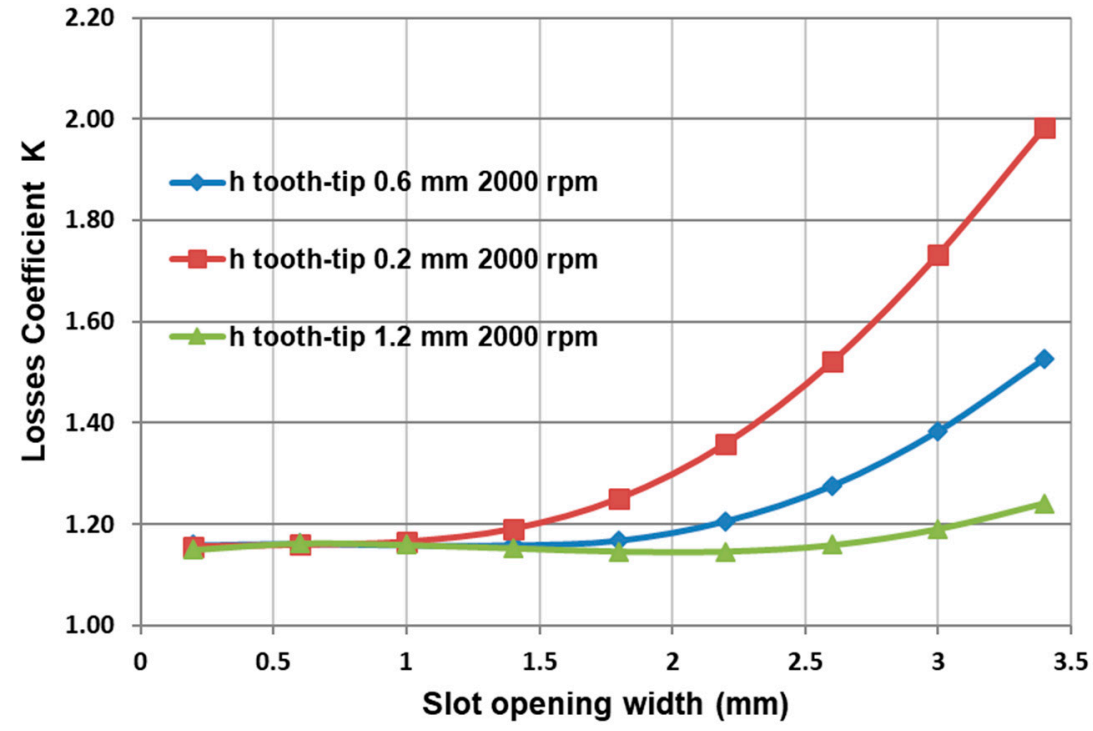

Figure 33. h tooth-tip and slot opening width effect on $K$.

The optimization of the stator dimensions with this type of winding is very limited, because the constraints imposed on our motor limited our choices for the dimensions that make up the stator. Our simulations have been centered on the height of the stator yoke $h_{c s}$ by fixing the total stator thickness $e_{S}=7 \mathrm{~mm}$, the slot diameter $d_{e n c}=3.5 \mathrm{~mm}$ and the external diameter $d_{\text {ext }}=110 \mathrm{~mm}$. Figure 34 represents the torque obtained for sinusoidal currents of 100 A RMS.

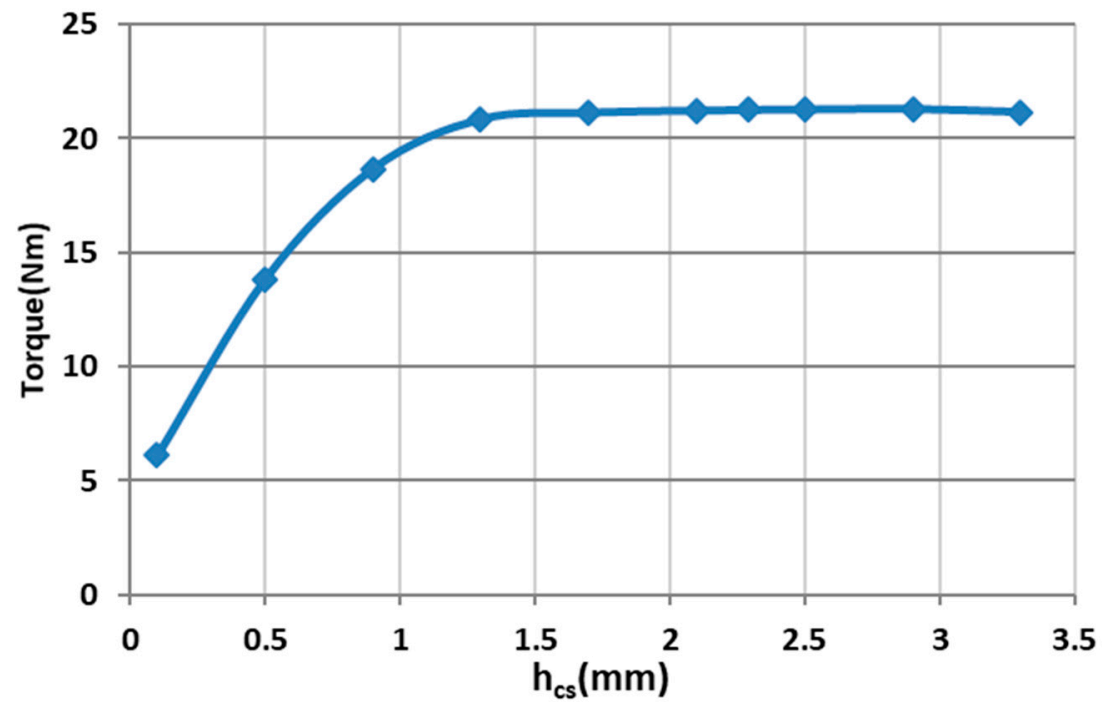

Figure 34. FEA results for $h_{c S}$ effect on the Torque.

We notice that the torque is at its maximum for $h_{c s}>1.3 \mathrm{~mm}$.

The influence of the height of the stator yoke on the torque has been shown, and we check its influence on the motor efficiency. The calculation was performed for each point with ANSYS using Equation (30).

$$
\eta=\frac{T \cdot \Omega}{T \cdot \Omega+\sum \text { Losses }}
$$

The results are shown in Figure 35. 


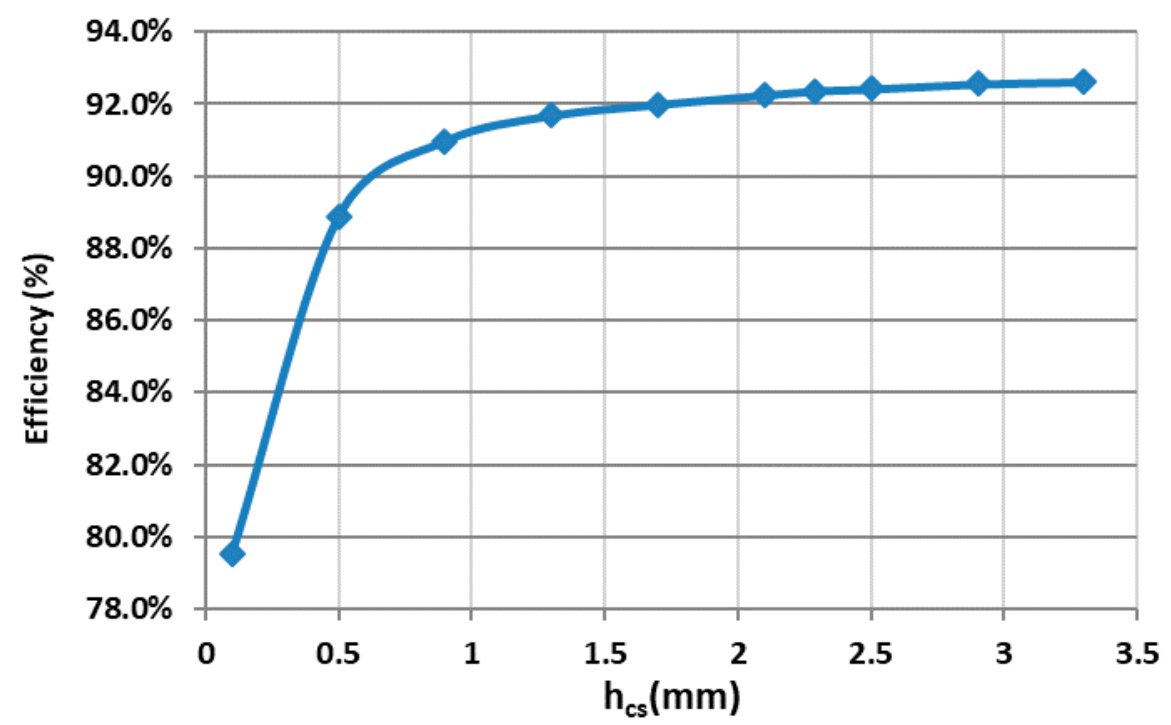

Figure 35. FEA results for $h_{c s}$ effect on Efficiency.

For stator-yoke thickness $h_{c S}$ equal to $1.3 \mathrm{~mm}$ we obtained the maximum torque and found that the efficiency increased very little from this value as shown in Figure 35. Table 4 shows a comparison between the prototype and the motor optimized by the previous calculations. The results show us an improvement in efficiency for the same torque, and for the same current of $100 \mathrm{~A}$, the torque would be $23 \mathrm{~N} \cdot \mathrm{m}$.

Table 4. Comparison between the prototype and the optimized motor.

\begin{tabular}{lcc}
\hline \multicolumn{1}{c}{ Designation } & Prototype & Optimized Motor \\
\hline Stator thickness $e_{S}[\mathrm{~mm}]$ & 7 & 5 \\
$h_{\text {cs }}[\mathrm{mm}]$ & 2.24 & 1.3 \\
$h_{\text {isthm }}[\mathrm{mm}]$ & 1.16 & 0.2 \\
$O_{\text {enc }}[\mathrm{mm}]$ & 0.4 & 0.4 \\
$D_{\text {enc }}[\mathrm{mm}]$ & 3.6 & 3.5 \\
Magnet height [mm] & 4.5 & 4.5 \\
Magnet width [mm] & 4.84 & 5 \\
Current [A] & 100 & 92 \\
Torque [N·m] & 21 & 21 \\
Winding Losses [W] & 203 & 178 \\
Stator core loss [W] & 63 & 70 \\
Rotor Core loss [W] & 0.74 & 0.61 \\
Losses due to induced & 0.82 & 0.69 \\
currents in the Magnets [W] & 92 & 93 \\
Efficiency [\%] & &
\end{tabular}

The prototype produced and tested has similar characteristics to the optimized motor. The optimized motor has an efficiency with less total losses. The reduction of the current reduces the Joule losses in the bars. The large number of smaller magnets minimizes the losses in the magnets and in the rotor. The stator iron losses are higher because the reduction in the size of the yoke increases the induction in the stator and, therefore, the losses. This study is to be taken into account in the future sizing of small-power cylindrical bar motors.

\subsection{Influence of Number of Slot/Numer of Pole}

For our application, use 3 and $4 \mathrm{~mm}$ diameter bars. The use of large bars in combination with a large number of slots would lead to narrow stator teeth and, therefore, the induction would quickly reach saturation which would limit the choice of "Number of 
slots/Number of poles" and study the influence of the number of slots and the number of poles.

In Table 5, we provide the results for each optimized motor for each pair "Number of slots/Number of poles" for the same torque with a constant external diameter.

Table 5. Summary of the FEA results for different $\mathrm{N}_{\mathrm{s}} / 2 . \mathrm{p}$.

\begin{tabular}{lcccc}
\hline Number of Slots/Number of Poles & $\mathbf{5 1 / 5 2}$ & $\mathbf{4 5 / 4 6}$ & $\mathbf{3 9 / 4 0}$ & $\mathbf{3 3 / 3 4}$ \\
\hline Dia bar [mm] & 3 & 4 & 4 & 4 \\
Stator thickness $e_{S}[\mathrm{~mm}]$ & 5 & 6 & 6.5 & 7.1 \\
Air gap radius [mm] & 50 & 49 & 48.5 & 47.9 \\
$h_{\text {cs }}[\mathrm{mm}]$ & 1.3 & 1.2 & 1.7 & 2.3 \\
$h_{\text {isthm }}[\mathrm{mm}]$ & 0.2 & 0.2 & 0.2 & 0.2 \\
$O_{\text {enc }}[\mathrm{mm}]$ & 0.4 & 0.4 & 0.4 & 0.4 \\
$D_{\text {enc }}[\mathrm{mm}]$ & 3.5 & 4.6 & 4.6 & 4.6 \\
Magnet height [mm] & 4.5 & 4.5 & 4.5 & 4.5 \\
Magnet width [mm] & 5 & 5.6 & 6.4 & 7.5 \\
Current [A] & 92 & 105 & 112 & 127 \\
Torque [N·m] & 21 & 21 & 21 & 21 \\
Winding Losses [W] & 178 & 126 & 118 & 124 \\
Core loss [W] & 71 & 76 & 69 & 58 \\
Efficiency [\%] & 93 & 94.1 & 94.4 & 94.5 \\
\hline
\end{tabular}

The results show that reducing the number of poles and slots would increase the efficiency but would increase the current to obtain the same torque. This increase in current would create a dimensioning constraint on the power supply. This study has shown the interest of integrating in the dimensioning of the influence of the ratio of Number of slots/Number of poles.

\section{Conclusions}

This paper presented the feasibility and interest of using a cylindrical conductor bar for the winding of a low voltage motor for electric propulsion. The use of solid conductors (not wired) for our winding applications results in increased Joule losses in the winding. The study principle was presented and several analytical models for the calculation of the additional loss coefficient were studied and compared to a finite element simulation. Three analytical models can be used up to a frequency of $1000 \mathrm{~Hz}$ for a cylindrical bar winding. Previous and recent studies have shown the value of such windings. The important element in the design of a winding is the minimization of the winding overhang. By using a dental winding by group, we were able to make inter-spiral connections without any particular mechanical feasibility constraints.

The first objective of this study was to show the feasibility of using a cylindrical bar by building and testing a prototype $\left(4.5 \mathrm{~kW}\right.$ and $\left.N_{\text {nominal }}=1500 \mathrm{rpm}\right)$ with an efficiency of $92 \%$. To obtain these performances, of the motor requires a large number of poles $N_{R}=52$ with $N_{S}=51$ stator teeth. The designed prototype has been characterized and tested and the experimental results are equivalent to those made by finite element simulation. For this purpose, an experimental bench had to be designed in order to be able to make measurements with respect to low voltage and high-current electrical stresses. The experimental and simulation tests confirmed the analytical models of the additional loss coefficient.

Finally, to optimize the slots of this type of winding with a round bar, the parametric study presented the results, taking into account the influence of the dimensions of the stator for the application presented here. The impact of the number of slots and poles has also been studied and resulted in an efficiency of $94.5 \%$, but this study must take into account the converter and the motor power supply. When optimizing the parameters of the slot, the simulation results showed that the realized prototype has a similar performance to the optimized motor. 
The presented results show the interest of using massive cylindrical bars for the realization of windings for electric vehicles of small power.

Author Contributions: M.A. did the main of the conceptualization, methodology, simulation, experimental work and writing of the article. P.E. did the main of the conceptualization, methodology, experimental work, writing, editing and review of the article. The design of the prototype and all parts was supervised by D.M., N.B. and L.P. did the main of the conceptualization and methodology. All authors have read and agreed to the published version of the manuscript.

Funding: This research received no external funding.

Data Availability Statement: The study did not report any data.

Acknowledgments: The authors thank the Occitanie region of France for their financial support for the PhD student's scholarship.

Conflicts of Interest: The authors declare no conflict of interest.

\section{References}

1. ICAO Environmental Report 2016; The Environment Branch of the International Civil Aviation Organization (ICAO): Montréal, QC, Canada, 2016; Available online: https://www.icao.int/environmental-protection/pages/env2016.aspx (accessed on 2 September 2019).

2. Troncon, D.; Alberti, L.; Bolognani, S.; Bettella, F.; Gatto, A.; Agritalia, C.; Spa, C. Electrification of agricultural machinery: A feasibility evaluation. In Proceedings of the Fourteenth International Conference on Ecological Vehicles and Renewable Energies (EVER), Monte-Carlo, Monaco, 8-10 May 2019. [CrossRef]

3. Postiglione, C.; Collier, D.; Dupczak, B.; Heldwein, M.; Perin, A. Propulsion system for an all electric passenger boat employing permanent magnet synchronous motors and modern power electronics. In Proceedings of the Electrical Systems for Aircraft, Railway and Ship Propulsion, Bologna, Italy, 16-18 October 2012. [CrossRef]

4. 2006/95/EC. The European Parliament's Low Voltage Directive, Official Journal of the European Union. 2016. Available online: https:/ / www.legifrance.gouv.fr/jorf/id/JORFTEXT000000696472 (accessed on 14 February 2020).

5. Matt, D.; Boubaker, N.; Aitakkache, M.; Enrici, P.; Huselstein, J.J.; Martire, M. High power very low voltage motor for electric vehicle. In New Perspectives on Electric Vehicles; IntechOpen: London, UK, 2020. [CrossRef]

6. Enrici, P.; Jac, J.; Ziegler, N.; Dumas, F.; Matt, D. Actuators with Toothed Coupling for the Electrification of a landing gear. IET Electr. Power Appl. 2018, 12, 739-746. [CrossRef]

7. Rezzoug, A.; El-Hadi Zaim, M. Non-Conventional Electrical Machines, 1st ed.; Wiley-ISTE: London, UK, 2013; ISBN 978-1-118-60410-6.

8. Bianchi, N.; Berardi, G. Analytical Approach to Design Hairpin Windings in High Performance Electric Vehicle Motors. In Proceedings of the Energy Conversion Congress and Exposition (ECCE), Portland, OR, USA, 23-27 September 2018. [CrossRef]

9. Cai, W.; Fultton, D.; Congdon, C.L. Multi-Set Rectangular Copper Hairpin Windings for Electric Machines. U.S. Patent Application US7034428 B2, 25 April 2006.

10. Cci, W. Terminals and Connections between multi-Set Segmented Hairpin Windings. U.S. Patent Application US20080042508 A1, 21 February 2008.

11. Enrici, P.; Boubaker, N.; Matt, D. Bar Winding for the Low-Voltage Motorization of an Electric Tractor. In Proceedings of the International Conference on Electrical Machines (ICEM), Gothenburg, Sweden, 23-26 August 2020. [CrossRef]

12. Matt, D.; Boubaker, N. Very Low Voltage and High Efficiency Motorisation for Electric Vehicles. In Emerging Electric MachinesAdvances, Perspectives and Applications; IntechOpen: London, UK, 2021. [CrossRef]

13. Enrici, P.; Meny, I.; Matt, D. Conceptual Study of Vernier Generator and Rectifier Association for Low Power Wind Energy System. Special Issue Power Converter of Electric Machines, Renewable Energy Systems, and Transportation. Energies 2021, $14,666$. [CrossRef]

14. Field, A. Eddy currents in large slot-wond conductors. Trans. AIEE 1905, XXIV, 761-788. [CrossRef]

15. Belot, A. Course of the Ecole supérieure d'Electricité. In Calcul des Machines Electriques Tournantes; ESE: Gif-sur-Yvette, France, 1976.

16. Ondel, O. Diagnostic par Reconnaissance Des Formes: Application à un Ensemble Convertisseur-Machine Asynchrone. Ph.D. Thesis, Ecole centrale de Lyon, Écully, France, 2006.

17. Boubaker, N. Study of Atypical Losses in High Performance Permanent-Magnet Synchronous Machines for Aircraft Applications. Ph.D. Thesis, University of Montpellier, Montpellier, France, 2016.

18. Piscini, L. Study of a High Frequency and High Performance Machine for an Aeronautical Application. Ph.D. Thesis, University of Montpellier, Montpellier, France, 2020.

19. Piscini, L.; Matt, D.; Gimeno, A.; Boubaker, N. Contribution on AC bar windings losses reduction for a high frequency and high performance machine for aeronautical application. In Proceedings of the 19th International Symposium on Electromagnetic Fields in mechatronics, Electrical and Electronic Engineering (ISEF), Nancy, France, 29-30 August 2019. [CrossRef]

20. Gillon, E. Electrotechnique-Machines Electriques, Volume II. In Notions Complémentaires, 3rd ed.; Dunod Éditeur: Paris, France, 1964. 
21. Liwschitz, M. Calcul des Machines Électriques; Tome, I., Ed.; Editions SPES: Lausanne, Switzerland, 1967.

22. Kostenko, M.; Piotrovski, L. Machines à Courant Alternatif. Machines Électriques, 3rd ed.; Tome II, Edition de Moscou; Technique soviétique: Moscou, Russia, 1969.

23. Alger, P.L. Induction Machines; Gordon and Breach: Montreux, Switzerland, 1970.

24. Jufer, M. Electromécanique; Éditions Dunod: Paris, France, 1986.

25. Khaorapapong, T. Modélisation D'ordre Non Entier Des Effets de Fréquence Dans Les Barres Rotoriques D'une Machine Asynchrone. Ph.D. Thesis, Institut National Polytechnique de Toulouse, Toulouse, France, 2001.

26. Dowell, P.L. Effects of eddy currents in transformer windings. Proc. IEE 1966, 113, 1387-1394. [CrossRef]

27. Ferreira, A. Improved analytical modeling of conductive losses in magnetic components. IEEE Trans. Power Electron. 1994, 9 , 127-131. [CrossRef]

28. Emde, F. Einseitige Stromverdrängung in Ankernuten. Elektrotechnik Masch. 1908, 26, 703-707, 726-731.

29. Dreyfus, L. Wirbelstromverluste in massiven Ankerleitern bei Leerlauf. Arch. Elecktrotechnik 1917, 6, 327-358. [CrossRef]

30. Roth, E. Etudes des pertes supplémentaires dans les barres câblées. Rev. Générale L'electricite 1917, 2, 323-336.

31. Roth, E. Barre câblées et barres subdivisées dans les machines à courant alternative. Rev. Générale L'electricite 1918, 4, 192-198.

32. Butterworth, S. Eddy-Current Losses in Cylindrical Conductors, with Special Applications to the Alternating Current Resistances of Short Coils. Philos. Trans. R. Soc. Lond. Ser. A Contain. Pap. A Math. Phys. Character 1922, 222, 57-100. [CrossRef]

33. Lyon, W.V. Heat losses in the conductors of alternating current machines. Trans. Am. Inst. Electr. Eng. 1921, XL, 1361-1409. [CrossRef]

34. Lyon, W.V. Heat losses in stranded armature conductors. J. AIEE 1922, 41, 37-49. [CrossRef]

35. Oberrelt, K. Zusätzliche Wirbelstromverluste in Nutenleitern infolge eindringenden Luftspaltfeld (Additional eddy current losses in slot conductors due to air gap field). Arch. Elektrotechnik 1978, 60, 121-127.

36. Reatti, A.; Kazimierczuk, M. Comparison of various methods for calculating the ac resistance of inductors. IEEE Trans. Magn. 2002, 38, 1512-1518. [CrossRef]

37. Wrobel, R.; Mlot, A.; Mellor, P.H. Investigation of end-winding proximity losses in electromagnetic devices. In Proceedings of the XIX International Conference on Electrical Machines (ICEM), Rome, Italia, 6-8 September 2010. [CrossRef]

38. Paradkar, M.; Böcker, J. Analysis of eddy current losses in the stator windings of IPM machines in electric and hybrid electric vehicle applications. In Proceedings of the 8th IET International Conference on Power Electronics, Machines and Drives (PEMD), Glasgow, UK, 19-21 April 2016. [CrossRef]

39. Stoll, R.L. The Analysis of Eddy Current; Clarendon Press: Oxford, UK, 1974.

40. Belkaid, Z. Models and Tools for the Design of HF Magnetic Components Dedicated to Power Electronics. Ph.D. Thesis, University of Montpellier, Montpellier, France, 2016.

41. Wikipedia. Available online: https://fr.wikipedia.org/wiki/Fonction_de_Kelvin-Bessel (accessed on 22 October 2021).

42. Swann, S.A. Effective resistance and reactance of a solid cylindrical conductor placed in a semi-closed slot. Proc. IEE Monogr. 1962, 527, 611-615. [CrossRef]

43. Levasseur, A. Nouvelles formules, valables à toutes les fréquences, pour le calcul rapide de l'effet Kelvin. J. Phys. Radium 1930, 1, 93-98. [CrossRef]

44. Filliau, G.; Bondu, A.; Mazodier, L. Le Navire Tout Électrique-Propulsion et Production D'énergie. Technique de l'ingénieur, D5610v1. 2000. Available online: https://www.techniques-ingenieur.fr/base-documentaire/archives-th12/archives-reseauxet-applications-tiadc/archive-1/le-navire-tout-electrique-d5615/ (accessed on 22 October 2021). 